\title{
ОЦЕНКА РИСКА СТАТЬ ИНВАЛИДОМ В РОССИИ: ОПЫТ МОДЕЛИРОВАНИЯ ПО ДАННЫМ ЛОНГИТЮДНОГО ВЫБОРОЧНОГО ИССЛЕДОВАНИЯ
}

\author{
ОКСАНА КУЧМАЕВА, НАТАЛЬЯ КАЛМЫКОВА, АНТОН КОЛОТУША
}

\begin{abstract}
Статья посвящена моделированию риска инвалидности в России на основе микроданньх. Необходимость оценки риска инвалидности обусловлена значительными масштабами процесса инвалидизаџии в России и его дифференциицией для социально-демографических групп населения. Цель исследования состоит в определении факторов, влияющих на риск наступления инвалидности в России. Сложность оценки риска инвалидности связана с отсутствием репрезентативных мониторинговых обследований инвалидности, а также данных о смертности лии с инвалидностью, в том числе по возрастным группам и заболеваниям. Для моделирования риска стать инвалидом использовали данные «Российского мониторинга экономики и здоровья» (НИУ ВШЭ) за период с 2003 по 2018 г. Объем выборки составил более 125 тыс. респондентов, из которых 519 индивидов получили инвалидность. На основе регрессий Кокса была построена серия моделей выжсивания для оценки влияния социоэкономических факторов на риск для здорового человека стать инвалидом. Для расчетов использован программный пакет IBMSPSS 25.0. Наиболее заметно риск инвалидности растет для мужчин и для женщин после 50-летнего возраста и к возрасту 60 лет достигает 3-4\%. Наблюдаются различия в риске стать инвалидом у мужчин и женщин, а также в зависимости от уровня образования, брачного статуса и местности проживания. Выявлено наличие значимого превышения риска стать инвалидом у представителей отдельных профессиональных групп. Наиболее высокий риск стать инвалидом II группы наблюдается у специиалистов высшего и среднего уровня квалификаџии, офисных служащих и специалистов по работе с клиентами, работников сферы торговли и услуг, а также у квалифицированных работников сельского, лесного и рыбного хозяйства. Дифференциация риска получения инвалидности в пожилом возрасте обусловлена накопленными дефектами здоровья, в значительной части случаев связанными с профессиональной деятельностью, а также различным доступом к медицинским услугам и информации о получении инвалидности.
\end{abstract}

Ключевые слова: инвалидность в России, риск стать инвалидом, факторы инвалидности, регрессия Кокса, вероятность инвалидности, факторы инвалидности, источники данных о инвалидности.

Актуальность проблемы. Мировое сообщество консолидирует усилия для обеспечения принципа доступности для инвалидов основных прав и свобод человека, закрепленного в Конвенции ООН о правах инвалидов (ратифицирована Российской Федерацией в 2012 г.). Речь идет о преодолении дискриминации лиц по признаку инвалидности, обеспечении социальной инклюзии инвалидов - их включении в жизнь общества: в трудовую деятельность, образование, спорт, религию, политику и др.

ОКСАНА ВИКТОРОВНА КУчмАЕВА (kuchmaeva@yandex.ru), МОСКОВСКИЙ ГОСУДАРСТВЕННЫЙ УНИВЕРСИТЕТ имЕНИ М.В. ЛОМОНОСОВА, РОсСия.

НАТАЛЬЯ МИХАЙЛОВНА КАЛМЫКОВА (natalia@econ.msu.ru), МОСКОВСКИЙ ГОСУДАРСТВЕННЫЙ УНИВЕРСИТЕТ иМЕНИ М.В. ЛОМОНОСОВА, РОССИЯ.

АНТОН ВАСИЛЬЕВИЧ КОЛОТУША (tony_kol@mail.ru), МОСКОВСКИЙ ГОСУДАРСТВЕННЫЙ УНИВЕРСИТЕТ ИМЕНИ М.В. ЛомоносовА, Россия.

СТАТЬЯ ПОДГОТОВЛЕНА В РАМКАХ ГРАНТА РФФИ «ВЛИЯНИЕ ЧЕЛОВЕЧЕСКОГО КАПИТАЛА НА НАСТОЯЩИЙ И БУДУЩИЙ ЭКОНОМИЧЕСКИЙ РОСТ в РОССИИ» (19-29-07546).

СТАТЬЯ ПОСТУПИЛА В РЕДАКЦИЮ В ОКТЯБРЕ 2020 Г. 
Внимание к положению и соблюдению прав инвалидов обусловлено увеличением абсолютной и относительной численности людей с инвалидностью, долговременной мировой и российской тенденцией, в значительной степени связанной с достижениями медицины и повышением ценности человеческой жизни в обществе.

По данным ВОЗ (Всемирная организация здравоохранения 2020), инвалиды относятся к наиболее изолированным группам населения в мире. Они характеризуются в среднем более низкими показателями здоровья, достижений в образовании и участия в экономическом развитии, а также чаще составляют малообеспеченное население, нежели люди без инвалидности. Всё вышеперечисленное указывает на то, что инвалидизация населения - один из факторов возникновения потерь человеческого капитала страны. В России, согласно данным Росстата (Росстат 2020), масштабы инвалидности в последние годы несколько снизились, но всё же остаются весьма высокими: общая численность инвалидов за последние 7 лет сократилась с 13,1 до 11,9 млн человек, на 1000 человек населения на начало 2020 г. приходилось немногим более 80 инвалидов. Рост общего числа инвалидов происходит в детских, а также в молодых трудоспособных возрастах, что является следствием ухудшения здоровья населения именно в этих группах. Увеличение численности детей с инвалидностью на фоне сокращения общей и первичной численности инвалидов является общемировым трендом (Кулагина 2016).

Сложившаяся ситуация актуализирует необходимость получения достоверных оценок риска инвалидности в условиях увеличения ее масштабов и необходимости активизации социальной политики в интересах инвалидов.

Цель исследования состоит в определении факторов, влияющих на риск наступления инвалидности взрослого населения.

\section{ДИНАМИКА И МАСШТАБЫ ИНВАЛИДНОСТИ В РОССИИ}

Численность инвалидов в России (по данным Пенсионного фонда России) на начало 2020 г. составила 11875 тыс. человек (8\% от всего населения страны), при этом больше половины инвалидов - женщины (57\%). Расчет на основе данных Комплексного наблюдения условий жизни населения показывает, что на долю инвалидов среди лиц старше 15 лет в России в 2016 г. приходилось 6,7 \% населения (Росстат 2016), в 2018 г. - 6,9\% (Росстат 2018). Данные выборочных опросов РАНХиГС, проводимых с 2013 г., демонстрируют, что около $8 \%$ респондентов имеют официальный статус инвалида. При этом по регионам отклонение оценок выборочного опроса от данных Росстата колеблется от $-2,4$ п.П. до 0,5 п.п. (Бурдяк, Тындик 2016). Однако, несмотря на определенные расхождения в величине показателей, различные источники указывают на масштабность распространенности инвалидности в населении страны и демонстрируют близость оценок.

Преобладание мужчин среди инвалидов наблюдается в молодых и зрелых возрастах (64\% в возрастах 31-54 года), однако в силу более низкой продолжительности жизни российских мужчин в старших возрастах (старше трудоспособного) их доля сокращается до 33\%. Среди инвалидов старше 60 лет наблюдается значительный перевес женщин: 
в возрасте 64 года на 1000 инвалидов-мужчин приходится 1200 инвалидов-женщин, в возрасте 70 лет - уже 1559, 75 лет - 2016.

Вышесказанное доказывает необходимость оценок последствий инвалидности с учетом распределения инвалидов по полу.

В целом в 2013-2020 гг. численность инвалидов сокращалась (почти на 1,4\% ежегодно). Отрицательная динамика наблюдается для I и II групп инвалидности ${ }^{1}$, характеризующихся наиболее тяжелыми последствиями для здоровья (таблица 1).

Таблица 1. Динамика численности инвалидов в России, 2013 - 2020

\begin{tabular}{|c|c|c|c|c|c|c|c|c|}
\hline & 2013 & 2014 & 2015 & 2016 & 2017 & 2018 & 2019 & 2020 \\
\hline Всего инвалидов, тыс. человек & 13082 & 12946 & 12924 & 12751 & 12261 & 12111 & 11947 & 11875 \\
\hline \multicolumn{9}{|l|}{ в том числе: } \\
\hline I группы & 1496 & 1451 & 1355 & 1283 & 1309 & 1466 & 1433 & 1422 \\
\hline II группы & 6833 & 6595 & 6472 & 6250 & 5921 & 5552 & 5356 & 5209 \\
\hline III группы & 4185 & 4320 & 4492 & 4601 & 4395 & 4442 & 4488 & 4556 \\
\hline дети-инвалиды & 568 & 580 & 605 & 617 & 636 & 651 & 670 & 688 \\
\hline $\begin{array}{l}\text { Средняя численность инвалидов } \\
\text { на } 1000 \text { человек населения }\end{array}$ & 91,3 & 90,1 & 88,4 & 87,0 & 83,5 & 82,5 & 81,4 & 80,9 \\
\hline
\end{tabular}

Источник: Данные Росстата. URL: https://rosstat.gov.ru/folder/13964?print=1

Динамика численности инвалидов в России в последние годы, основанная на данных официального учета, в определенной степени является отражением ужесточения правил назначения инвалидности. Снижение показателей общей инвалидности в первую очередь связано с устойчивым уменьшением с 2006 г. числа граждан, впервые признанных инвалидами в учреждениях медико-социальной экспертизы (МСЭ) (Владимирова и др. 2017: 46).

При этом растет численность инвалидов III группы, имеющих большей частью не слишком значительные ограничения по трудовой деятельности, а также детей-инвалидов. На фоне роста детской инвалидности несколько парадоксальным выглядит сокращение взрослой инвалидности. В структуре инвалидности доля инвалидов III группы в начале 2020 г. составила 38,4\%. Однако этот показатель очень дифференцирован по регионам страны: по данным за 2019 г., когда по стране в целом доля инвалидов III группы составляла $37,6 \%$, показатель колебался от $10 \%$ в Чеченской Республике до 50,6\% в Чувашской Республике.

Современный уровень инвалидности взрослых в России во многом является результатом ее роста в предыдущий период (в 2004-2006 гг.), причем наиболее быстрого в 2005 г. - в период проведения так называемой «монетизации льгот». Использование стандартизированного коэффициента первичной инвалидности по группам

\footnotetext{
1 Здесь и далее в работе использованы официально устанавливаемые группы инвалидности. Критерием для установления групп инвалидности служит степень выраженности стойких нарушений функций организма. Классификация критериев представлена в Приказе Министерства труда и социальной защиты РФ от 17 декабря 2015 г. № 1024н «О классификациях и критериях, используемых при осуществлении медикосоциальной экспертизы граждан федеральными государственными учреждениями медико-социальной экспертизы».
} 
доказывает, что в последние годы растет доля назначений более легкой инвалидности (Малева 2017: 72-74).

Уровень инвалидизации нарастает после 50 лет (рисунок 1) и достигает пиковых значений в возрастном интервале 85-94 года. Уже в возрастах старше 70 лет доля инвалидов составляет 30\% всего населения и продолжает увеличиваться до 45-46\% в преклонных возрастах 92-95 лет.

Более половины российских инвалидов (65\%) - люди в возрасте старше 60 лет, а в трудоспособных возрастах их около 30\%. Средний возраст российских инвалидов составил на начало 2019 г. 55,7 года для мужчин и 64,1 года для женщин (средний возраст всего населения - 36,8 и 41,9 года).

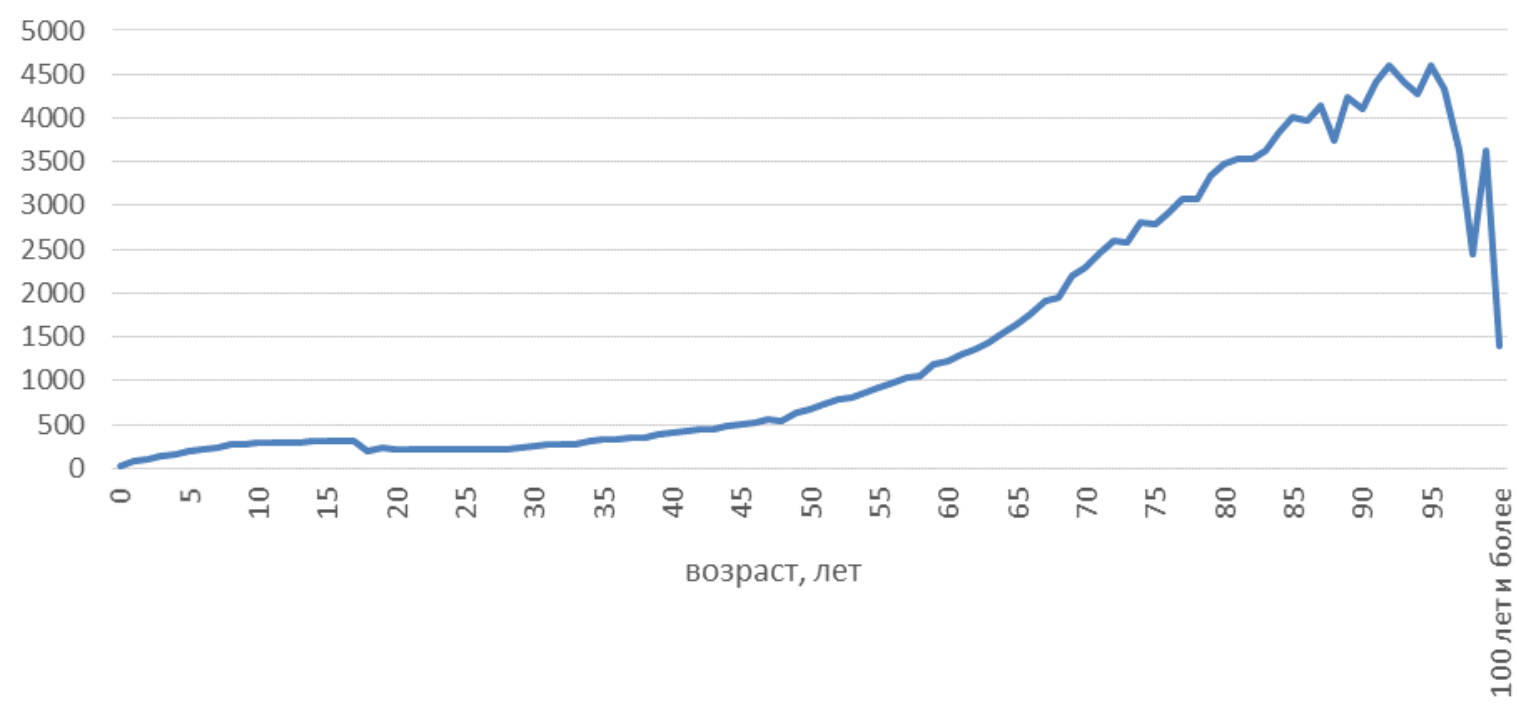

\section{Рисунок 1. Уровень инвалидности россиян, начало 2019 г., число инвалидов на 10 тыс. населения соответствующего возраста}

Источник: Рассчитано авторами на основе данных Росстата.

Возраст и пол - основные демографические характеристики, на которые обращают внимание исследователи при оценке динамики инвалидности: например, (Бурдяк, Тындик 2016) отмечают рост инвалидности с возрастом, смещение инвалидности в старшие и пожилые возраста, а также преобладание женщин среди инвалидов, что объясняется тем, что женщины больше прислушиваются к своему здоровью, субъективно склонны оценивать его хуже. Кроме этого, женщины преобладают численно в старших возрастах и при прочих равных - также в группе людей со статусом инвалидности. Аналогичные тенденции отмечены в исследовании (Иванова и др. 2019).

Наличие или отсутствие семьи у инвалидов, а также семейное состояние как фактор инвалидности практически не рассматриваются в российских исследованиях, видимо, поскольку в медицинской статистике (и регистре инвалидов) такая характеристика отсутствует, а в обследованиях, содержащих информацию о семейном статусе инвалида на дату обследования, невозможно установить его семейное положение в период получения инвалидности либо такие совокупности слишком малы. Как отмечают (Иванова и др. 2019), 
основываясь на данных микропереписи, основная нагрузка по уходу за инвалидами ложится на лиц, проживающих в том же домохозяйстве. Можно предположить, что наличие близких родственников может способствовать поддержанию здоровья лиц с инвалидностью, но при этом невозможно сделать вывод о влиянии наличия семьи на получение статуса инвалида. В исследованиях для стран с доступными панельными данными делается вывод о важности роли семьи в получении статуса инвалида. Используя метод близнецов для изучения получения статуса инвалидности, авторы (Ropponen, Svedberg 2019) приходят к выводу, что, наряду с особенностями состояния здоровья, семейное окружение может играть значимую роль в переходе из статуса здорового в статус больного и далее в статус инвалида. Влияние фактора семьи (наряду с типом занятости («белые воротнички» и «синие воротнички») на переход в состояние инвалидности подчеркивается также в работе (Helgadóttir et al. 2019).

Главное внимание в исследованиях отводится влиянию инвалидности на занятость, вовлеченности инвалидов в профессиональную деятельность и получению дохода от занятости (Демьянова, Лукьянова 2016; 2017; Кучмаева 2020), т. е. профессиональный статус и размер дохода выступают скорее как следствия инвалидности, а не как ее факторы. При этом образование и профессиональный состав инвалидов анализируют гораздо реже. Оценивая уровень инвалидности в России, (Бурдяк, Тындик 2016) отмечают, что среди инвалидов преобладают лица, проживающие в городской местности, имеющие низкий уровень образования, не занятые.

Катлер и Ллерас-Муней (Cutler, Lleras-Muney 2010) отмечают, что образовательный градиент в инвалидности объясняется образом жизни, в частности, отказом от курения и распространенностью ожирения, различиями в занятости и условиях труда, а также различиями в структуре заболеваемости. Уровень образования может оказывать влияние на состояние здоровья и инвалидность косвенно через степень ориентации на превентивные меры по охране собственного здоровья, информационные ресурсы (в частности, осведомленность о симптомах заболеваний, обладание информацией о возможностях получения медицинской помощи), финансовые ресурсы для обращения за платными медицинскими услугами, для лучшего питания, занятий спортом и др. (Вяльшина 2020).

Пик инвалидности в России приходится на послетрудоспособные возраста. Однако продолжительность трудовой жизни россиян увеличивается, в том числе растет занятость лиц в возрастах старше 60 лет. Вместе с тем в исследованиях демонстрируется существенная дискриминация на рынке труда людей по статусу инвалида (Демьянова, Лукьянова 2017), что в условиях недостатка трудовых ресурсов обращается в проблему не только для индивидуума, но и для экономики страны. Исследователи разделяют экономические потери от роста инвалидности на две группы: первая - затраты на социальную поддержку инвалидов и их семей, вторая - издержки, обусловленные незанятостью инвалидов. Так, только в 2015 г. потери в виде недопроизводства ВВП неработающими инвалидами составили 11,3 трлн руб. (Нацун, Шабунова 2018).

Все это подчеркивает актуальность оценки факторов риска инвалидности с учетом демографических и социально-экономических параметров. 


\section{МЕТОДЫ И ДАННЫЕ}

В российских публикациях, как правило, оцениваются не вероятности получения статуса инвалида в зависимости от индивидуальных характеристик, а распределение лиц со статусом инвалидности по различным социально-демографическим группам. В медицинских исследованиях в основном акцентируется внимание на заболеваниях, приводящих к инвалидности, и их распределению в зависимости от пола и возраста, по группам инвалидности. Прочие индивидуальные характеристики не принимаются во внимание, хотя социальная природа инвалидности в России подчеркивалась уже в конце 1990х гг. (Инвалиды в России... 1999).

Как правило, основное внимание уделяется структуре имеющихся контингентов инвалидов и ее изменению во времени, при этом процесс формирования этих контингентов не рассматривается из-за отсутствия адекватных ретроспективных панельных индивидуальных данных, охватывающих период до и после установления статуса инвалидности, или открытого доступа к таким данным. Прогнозы численности и состава инвалидов осуществляются на основе информации о поле и возрасте, группе инвалидности, с учетом данных о смертности (Васин 2017), отсутствие информации о социальноэкономических факторах инвалидности не позволяет учесть их в расчетах. О необходимости уточнения «профиля инвалидности» пишет (Кулагина 2016), включая в него такие индивидуальные характеристики, как возраст, пол, уровень физической активности, образование, доход, профессия, место жительства, миграционный статус, этническая принадлежность, при этом речь идет о структуре контингента лиц с инвалидностью на момент исследования, а не на момент получения статуса инвалидности. И в этом случае на первый план выходят демографические характеристике инвалидов (возраст и пол), а состав семьи рассматривается, как правило, только при анализе детской инвалидности.

В основном в зарубежных работах приводятся оценки риска инвалидности, связанного с определенными заболеваниями, причем факторами служат как объективные характеристики здоровья, так и поведенческие аспекты (двигательная активность, курение, потребление алкоголя и др.) (Heiland et al. 2019).

Риск получения инвалидности в зависимости от профессиональной деятельности оценивается главным образом в медико-социальных исследованиях. Так, (Мешков, Бухтияров, Вальцева 2020), анализируя причины инвалидности пожарных, отмечают воздействие вредных факторов производственной среды и высокое нервно-психическое напряжение, приводящие к повышению уровня инвалидности по причине болезней органов дыхания и системы кровообращения. На шведских панельных данных, включающих информацию о более чем 79 тыс. социальных работников и младшего медицинского персонала, (Leineweber et al. 2019) с использованием регрессии Кокса приходят к выводу, что специфические условия труда (в данном случае - высокий психологический риск, связанный с работой) могут быть фактором повышенного риска инвалидности.

В последние годы расширяется круг методов, используемых для оценки потерь здоровья и риска заболеваемости и инвалидности (Рамонов 2015). Теоретико- 
методологической основой настоящего исследования, направленного на выявление факторов риска инвалидности, послужила модель пропорциональных рисков (регрессия Кокса), разработанная для целей оценки величин риска наступления событий для индивида. Понятие риска в модели трактуется как количественная оценка шанса, что состояние, в котором пребывает респондент, для него прекратится. При этом применительно к демографическим событиям рассматриваемый процесс может носить как негативную коннотацию (риск, что респондент умрёт/станет инвалидом/разведётся), так и позитивную (риск выбытия респондента из числа холостых (вступит в брак), из числа больных (выздоровеет)). Однако в основном демографические эмпирические исследования, основанные на применении модели пропорциональных рисков, всё же сосредоточены на отрицательных по тональности процессах в силу естественности ассоциации риска с чемто негативным: с детской смертностью (Brandström et al. 1984), с материнской смертностью (Högberg, Wall, Broström 1986; Broström 1987), со смертностью от сахарного диабета (Andersen et al. 1985), со смертностью в зависимости от различного ежедневного уровня физической активности (McGregor et al. 2019).

Преимущество использования микроданных для анализа инвалидности по сравнению с подходами, используемыми в классическом демографическом анализе агрегированных данных, состоит в возможности рассматривать риски наступления событий для индивидов, не усредняя их для изучаемой группы, т. е. используя гипотезы однородности исследуемой совокупности. При наличии панельных данных возможно также вместо различий в инвалидности населения по полу, возрасту и другим показателям учесть индивидуальные характеристики, связанные с получением статуса инвалида, однако далеко не все российские обследования, включающие вопросы об инвалидности, предоставляют такую возможность.

Важная проблема - формирование необходимой информационной базы, позволяющей определить риск наступления инвалидности и оценить риск смерти для инвалидов (в сравнении с лицами, не имеющими инвалидности). Особенности различных источников информации об инвалидах в России с точки зрения их соответствия международным требованиям и подходам детально проанализированы в работе (Макаренцева, Васин, Хасанова 2016). Авторы пришли к выводу о необходимости формирования единой системы мониторинга инвалидности.

Программы целого ряда репрезентативных обследований Росстата позволяют получить интересную информацию о положении инвалидов в обществе. Нельзя не отметить микроперепись населения 2015 г., которая впервые позволила в рамках масштабного исследования получить информацию о наличии у россиян хронических заболеваний и инвалидности. Обследования рабочей силы, которое проводится Росстатом ежемесячно по представительной выборке, охватывающей 70 тыс. человек, ориентировано прежде всего на выявление ситуации в сфере занятости и безработицы и не предусматривает выделение инвалидов в представительную группу респондентов. Выборочное наблюдение доходов населения и участия в социальных программах в настоящее время проводится ежегодно с охватом 60 тыс. домохозяйств, с 2017 г. с периодичностью 1 раз в 5 лет выборка расширяется до 160 тыс. домашних хозяйств. Программа исследования позволяет получить 
информацию о размере и структуре доходов лиц с инвалидностью. Важное место в оценке положения инвалидов занимает Комплексное обследование условий жизни населения (КОУЖН), проводимое 1 раз в 2 года, охват составляет 60 тыс. домашних хозяйств. Программа исследования включает блок вопросов, позволяющих идентифицировать людей с инвалидностью и лиц, имеющих серьезные проблемы со здоровьем, выявить ситуацию в сфере социального обеспечения инвалидов, сформировать комплексное представление об условиях их жизни, возможностях в сферах занятости, получения образования, пользования услугами транспорта, об условиях проживания, доступности услуг (бытовых и предприятий торговли), потребностях в специализированной медицинской помощи и возможностях для отдыха. Программа КОУЖН включает отдельный опросник для лиц младше 15 лет, что позволяет получить ряд характеристик непосредственно для детей-инвалидов. Выборочное наблюдение качества и доступности услуг в сферах образования, здравоохранения и социального обслуживания проводится 1 раз в 2 года с охватом 48 тыс. домохозяйств. Программа исследования позволяет выделить группу людей с инвалидностью и соответственно выявить особенности и сложности процесса трудоустройства для инвалидов (в частности, частоту отказов в приеме на работу по состоянию здоровья), опыт и потребности в пользовании медицинскими и социальными услугами, условия проживания. Выборочное наблюдение рациона питания населения с 2013 г. планируется проводить 1 раз в 5 лет с охватом 45 тыс. домашних хозяйств. Программа исследования позволяет идентифицировать людей с инвалидностью и оценить специфику их рациона питания, информированность о здоровом питании, физическую активность

Однако все эти обследования, несмотря на наличие в программе вопросов, позволяющих охарактеризовать различные аспекты положения инвалидов в России, не позволяют оценить риск наступления инвалидности, поскольку не содержат вопроса о дате установления инвалидности.

Именно мониторинговый характер «Российского мониторинга экономики и здоровья» (НИУ Высшая школа... 2020), ежегодно проводимого НИУ ВШЭ (далее - РМЭЗ НИУ ВШЭ) на протяжении длительного периода времени, позволяет сформировать массив данных для оценки риска инвалидности. На основе микроданных РМЭЗ НИУ ВШЭ за период с 2003 по 2018 г. была построена серия моделей выживания с использованием регрессий Кокса, с помощью которых оценивали влияние социоэкономических факторов на риск для здорового человека стать инвалидом. Ключевыми достоинствами базы являются лонгитюдный характер данных (что соответствует задаче проведения анализа выживаемости, в основу которого входит изучение поведения индивидов во времени) и широкий арсенал вопросов одновременно и о характеристиках назначаемой респондентам инвалидности (год, месяц назначения, группа инвалидности), и об индивидуальных характеристиках респондентов (пол, возраст, профессиональный статус, тип населённого пункта проживания, семейное положение, уровень образования), что и предопределило наш выбор в пользу РМЭЗ как информационной базы исследования. Выбор периода исследования обусловлен наличием необходимых данных для характеристики инвалидности в программе исследования только за эти годы. Переходом в состояние 
инвалидности считали факт официального оформления инвалидности за календарный год до года обследования.

В настоящей работе мы не рассматривали формирование детских контингентов (детей-инвалидов и категорию «инвалиды детства») в связи со спецификой формирования инвалидности в детских возрастах и получения данных о детях-инвалидах из РМЭЗ, остановившись на оценках вероятностей стать инвалидов уже во взрослом возрасте. Выборка стратифицирована по полу и ограничена снизу возрастом «28 лет и старше», поскольку до возраста 28 лет структура выборки по уровню образования, занятости отличается высокой изменчивостью, спецификой влияния социальных факторов, определяющих установление/снятие официального статуса инвалида. Респонденты в возрасте 28 лет и старше в среднем достигли уровня образования, который впоследствии не будет существенно меняться. Также из выборки в моделях оценки риска стать инвалидом исключаются лица, получившие статус инвалидов (лица со сроком оформленной инвалидности от 2 лет и более, что соответствует методике модели, согласно которой после наступления события респондент выбывает из группы риска). Объем выборки составил более 125 тыс. наблюдений, из которых 519 индивидов получили инвалидность.

В качестве зависимой использовали переменную, характеризующую наличие у индивида официального статуса инвалида, полученного при осуществлении медикосоциальной экспертизы граждан соответствующими государственными учреждениями. Понимая все недостатки данного «объективного» подхода к определению инвалидности, неоднократно отмечавшегося специалистами (Всемирный доклад... 2011; Бурдяк, Тындик 2016), мы использовали именно официальный статус инвалида как критерий инвалидности в силу наличия в программе РМЭЗ всех раундов 2003-2018 гг. вопроса о его получении. Использование данного определения также позволяет проводить сопоставления между результатами выборочного обследования и данными официального статистического учета инвалидности.

Кроме того, отметим, что база РМЭЗ предлагает исследователям также спектр нозологических вопросов, однако он, к сожалению, обладает серьёзным недостатком: недоучётом возможности совместного наличия у респондента отдельных видов хронических заболеваний. Так, например, при построении моделей незначительная величина коэффициента при индикаторной переменной «заболевание почек» вовсе не будет означать, что индивиды, не имеющие заболеваний почек, в меньшей опасности получения инвалидности по сравнению с теми, у которых есть такие заболевания (поскольку не страдающие заболеванием почек в среднем могут иметь «букет» иных хронических заболеваний). Построение порядковой переменной количества хронических заболеваний будет носить малоинформативный характер, равно как и попытка построения непересекающихся групп по наличию разных комбинаций хронических заболеваний, в связи с чем было решено отказаться от использования нозологических характеристик респондентов в моделировании. Кроме того, в анкете отсутствует вопрос о том, вследствие какого заболевания была установлена инвалидность.

Набор ковариат включает переменные брачного статуса, местности проживания, последней законченной ступени образования, а также профессиональные группы. 
Изначально были сделаны оценки как вероятности стать инвалидом в целом, так и вероятности попасть в каждую из трех групп инвалидности по отдельности. В модели оценки вероятности умереть инвалиду группы инвалидности использовали как дополнительные регрессоры.

Методология исследования основана на использовании стратифицированных по полу моделей пропорциональных рисков.

Выбор в пользу этого типа модели обусловлен, с одной стороны, подтверждённой с помощью формального теста гипотезы независимости ковариат от времени, с другой также подкреплённым тестированием различий в повозрастной динамике риска стать инвалидом между полами (см. Приложение П1).

Преобразованное уравнение регрессии Кокса с поправкой на гендерные различия в риске стать инвалидом выглядит следующим образом:

$$
h_{i j}^{D I S}(t)=h_{0 j}^{D I S}(t) * \exp \left(\sum_{n=1}^{9} \beta_{n} O \text { occup }_{i n}+\sum_{m=1}^{6} \alpha_{m} \text { Marst }_{i m}+\sum_{l=1}^{23} \gamma_{l} E d u c_{i l}+\sum_{k=1}^{3} \delta_{k} \text { Status }_{i k}\right) .
$$

В представленном уравнении:

- $h_{i j}^{D I S}(t)$ - оцениваемый риск для і-го индивида ј-го пола стать инвалидом;

- $h_{0 j}^{D I S}(t)$ - одинаковый для всех индивидов ј-го пола базовый риск стать инвалидом;

- $\beta_{1}, \ldots, \beta_{9}-$ коэффициенты при переменных индикаторов профессионального статуса;

- Occup $_{1}, \ldots$, Occup $_{9}$ - индикаторы профессионального статуса (10 профессиональных групп, за базовую категорию брали индивидов без квалификации);

- $\alpha_{1}, \ldots, \alpha_{6}-$ коэффициенты при переменных индикаторов брачного статуса;

- Marst $_{1}, \ldots$, Marst $_{6}$ - индикаторы брачного статуса (7 групп, за базовую категорию брали индивидов, состоящих в браке);

- $\gamma_{1}, \ldots, \gamma_{23}-$ коэффициенты при переменных индикаторов последней законченной ступени образования;

- $E d u c_{1}, \ldots, E d u c_{23}$ - индикаторы последней законченной ступени образования (24 ступени от 0 классов школы до аспирантуры с дипломом, за базовую категорию брали индивидов, окончивших аспирантуру с получением диплома);

- $\delta_{1}, \ldots, \delta_{3}-$ коэффициенты при переменных индикаторов типа населённого пункта;

- Status $_{1}, \ldots$, Status $_{3}$ - индикаторы типа населённого пункта (4 группы - областной центр, город, посёлок городского типа (ПГТ) и село, за базовую категорию брали жителей сельской местности).

Коэффициенты показывают влияние каждого из факторов на изменение риска стать инвалидом. Так, например, коэффициент $\beta_{1}$, отражающий принадлежность респондента к группе военнослужащих, при прочих равных показывает, что у военнослужащего риск стать инвалидом в ехр $\left(\beta_{1}\right)$ раз выше, чем у работника без квалификации. Аналогичным образом интерпретируются значения остальных коэффициентов. 
По той же формуле оцениваются риски стать инвалидом определённой группы инвалидности - показатели $h_{i j}^{D I S_{-} 1}(t), h_{i j}^{D I S_{-} 2}(t)$ и $h_{i j}^{D I S_{-} 3}(t)$, которые отражают риск стать инвалидом I, II и III группы соответственно.

В модели оценки риска стать инвалидом возраст респондента в годах выступает в качестве переменной времени при введении дополнительного условия, что респондент ранее не учитывался в выборке как инвалид. Таким образом мы принимаем во внимание длительность периода здоровой жизни индивида. Наступление события инвалидности фиксируется благодаря вопросу о наличии зарегистрированной инвалидности, ответы на который перекодированы в бинарный вид. Респондент без зарегистрированной инвалидности находится в группе риска, чему соответствует значение «0» переменной, установленной в качестве статуса. Если индивид переходит в группу инвалидов, переменная статуса для него приобретает значение «1», этот респондент далее не участвует в наблюдении.

Для анализа данных обследования и построения моделей использован программный пакет IBMSPSS 25.0.

\section{ДОПУЩЕНИЯ И ОГРАНИЧЕНИЯ АНАЛИЗА}

Основные допущения вытекают из общей постановки модели пропорциональных рисков, к которым относятся следующие базовые предположения (Сох 1972):

1. все объясняющие переменные независимы;

2. влияние каждой объясняющей переменной на риск наступления события (стать инвалидом или умереть инвалиду) носит линейный характер;

3. риски наступления события для двух любых респондентов в любой отрезок времени носят пропорциональный характер и не зависят от времени.

Первая предпосылка хорошо соответствует нашим данным: по результатам построения коэффициентов сопряжённости Пирсона, применяемым к анализу категориальных переменных, выявлено лишь одно значение коэффициента, несущественно превышающее по модулю 0,5 , что свидетельствует об уровне связи между переменными в целом не выше среднего и, следовательно, об оправданности признания регрессоров независимыми. Почти все коэффициенты статистически значимы на уровне не менее $\alpha=0,1$ (см. Приложение П3). Две другие предпосылки обусловлены методикой построения модели регрессии Кокса. Гипотеза о линейном характере риска является одной из наиболее распространенных, часто используется в социально-демографических исследованиях, логична и применима в данном моделировании.

К иным ограничениям анализа, не связанным с характером модели, мы можем отнести:

- возможность селекции в данных (база не идеально репрезентирует население по социально-экономическому статусу: в частности, в выборку не попадают представители как маргинализированных групп, так и институционального населения 
(не проживающего в собственных домохозяйствах) с менее риск-аверсивными моделями поведения, что может приводить к смещению коэффициентов при факторах риска стать инвалидом или умереть инвалиду);

- возможность наличия ошибок 1-го и 2-го рода в учёте инвалидности в исходных данных: существует риск присутствия в исходной выборке как индивидов, отмеченных в качестве инвалидов, но реально не являющихся таковыми, так и упущенных фактических инвалидов, которых мы ошибочно принимаем за здоровых.

В таблице 2 представлена информация о сочетании ответов респондентов на вопрос о наличии зарегистрированной инвалидности и о том, насколько они могут по состоянию здоровья выполнять повседневные дела и обязанности. Распределение ответов не позволяет однозначно идентифицировать инвалидность на основе сочетания этих двух характеристик. Мы можем увидеть доминирование в выборке лиц, не отметивших проблем с повседневной работой $(85,4 \%$ от общего числа ответивших на вопросы), и абсолютное преобладание лиц без оформленной инвалидности. При этом в числе тех, кто не жалуется на физические проблемы с повседневной деятельностью, чуть более 95\% не имеют зарегистрированной инвалидности. Выбор респондентами варианта ответа, свидетельствующего о наличии «некоторых проблем» с осуществлением повседневных дел и обязанностей, неоднозначен у разных групп респондентов. В значительной части случаев на нем останавливались люди, не имеющие официального статуса инвалида (2/3 ответов). Из тех, кто указал полную физическую неспособность к осуществлению повседневной работы, напротив, примерно 2/3 отметили наличие оформленной инвалидности. Группа людей, указавших полную неспособность выполнять повседневные дела, и в которой могли бы наиболее надёжным образом присутствовать скрытые фактические инвалиды, составляет 12,7\% совокупности, что несколько превышает показатели официальной инвалидности, однако превышение не является критичным.

\section{Таблица 2. Доля лиц, имеющих инвалидность среди респондентов с разными оценками состояния здоровья, \%}

\begin{tabular}{l|c}
\hline \multicolumn{1}{c|}{$\begin{array}{c}\text { Варианты ответа на вопрос: «Насколько Ваше } \\
\text { состояние здоровья позволяет Вам осуществлять } \\
\quad \text { повседневные дела и обязанности?» }\end{array}$} & $\begin{array}{c}\text { Доля лиц, имеющих официальный статус инвалида, } \\
\text { \% к числу респондентов, имеющих те или иные } \\
\text { проблемы со здоровьем }\end{array}$ \\
\hline $\begin{array}{l}\text { Нет проблем с осуществлением повседневных дел и } \\
\text { обязанностей (8826) }\end{array}$ & 4,7 \\
Есть некоторые проблемы с осуществлением & 34,3 \\
повседневных дел и обязанностей (13600) & 61,8 \\
Вы не способны осуществлять свои повседневные дела & 41,7 \\
и обязанности (1310) & 0,0 \\
Затрудняюсь ответить (12) & 9,4 \\
Нет ответа (8) &
\end{tabular}

Источник: Расчеты авторов на основе данных РМЭЗ 2003-2018 г2.

Примечание: В скобках - численность респондентов, выбравших тот или иной вариант ответа на вопрос: «Насколько Ваше состояние здоровья позволяет Вам осуществлять повседневные дела и обязанности?» 
Таким образом, можно признать масштабы возможной ошибки учёта инвалидов 2-го рода незначительными. Поскольку вопрос о том, как состояние здоровья позволяет осуществлять повседневную физическую работу, задавался респондентам только в волну 2005 г., мы проводим анализ с учетом допущения, что и в другие годы обследования пропорции в результатах ответов на вышеуказанные вопросы в целом близки к пропорциям на данных обследования за 2005 г.

Суммируя, мы строим модели пропорциональных рисков на микроданных индивидуального уровня РМЭЗ НИУ ВШЭ за период с 2003 по 2018 г., принимая к сведению риск существования внешней селекции, устранить которую не представляется возможным, а также накладывая возрастное ограничение на выборку «28+» с целью минимизации масштабов возможной ошибки учёта инвалидов 1-го рода и признавая угрозу ошибки 2-го рода несущественной.

Также с учётом того, что в выборке наблюдается серьёзный недостаток наблюдений по некоторым подгруппам внутри категориальных групп, в частности в выборке присутствовало сравнительно немного респондентов, относящихся к профессиональным подкатегориям «Военнослужащих» и «Квалифицированных работников сельского, лесного хозяйства и рыбоводства» (см. Приложения П2, П4), мы провели перевзвешивание наблюдений с последующей оценкой моделей на укрупнённых группах.

\section{РеЗУЛЬТАТЫ АНАЛИЗА}

Статистически значимых различий в риске стать инвалидом не было только у представителей I группы инвалидности, что обусловлено незначительной представительностью в выборке данной категории респондентов (в исходной выборке всего 9 человек). Во многом численность респондентов, имеющих инвалидность I группы, уменьшилась за счет наличия пропусков в необходимых для построения модели данных. Столь малое количество наблюдений не позволило построить достоверную модель. Остальные же модели построены для более широкой совокупности индивидов: за все волны из чуть более чем 125 тыс. респондентов, являвшихся потенциальными инвалидами в возрасте от 28 лет и старше, 519 человек получили инвалидность. Из них 188 человек получили инвалидность II группы, а 311 человек - инвалидность III группы. Общая выборка инвалидов выглядит сбалансированной по полу (из 519 человек 246 - мужчины, 273 женщины), равно как и выборка из 311 инвалидов III группы, в которой насчитывается 167 мужчин и 144 женщины. В разрезе же II группы есть некоторые гендерные диспропорции с перекосом в сторону инвалидов женского пола: 188 инвалидов II группы разделяются на 65 мужчин и 123 женщины.

Это подтолкнуло нас к укрупнению используемых в регрессионном анализе подкатегорий переменных: мы рассчитали относительные веса каждой из них в общем объёме наблюдений данной категории переменных. Так, например, с учётом наложенных на выборку ограничений по возрасту «28+» и требований, чтобы в выборку попадали только индивиды, не являющиеся состоявшимися инвалидами (которые не регистрировали инвалидность в позапрошлом году и ранее), общее число наблюдений, в которых 
респондент указал принадлежность к одной из 10 профессиональных групп, было 125377. Из них 774 наблюдения соответствовали военнослужащим. Отсюда вероятность того, что мы случайным образом из общего объёма валидных наблюдений вытащим военнослужащего, составляет $p_{i, \text { военнослужащий,профессиональные группы }}=\frac{774}{125377}=0,00617$, т. е. немногим более 6\%. Таким образом, для каждой из категорий переменных были рассчитаны доли подкатегорий вида $p_{i j k}$, для категорий переменных, описывающих брачный статус, уровень образования, принадлежность профессиональной группе и населенный пункт проживания - соответственно. Далее, полагаясь на результаты корреляционного анализа на основе коэффициентов сопряжённости Пирсона, мы имеем основание принять рассматриваемые категории переменных независимыми друг от друга, что оправдывает расчёт условных вероятностей того, что данный респондент будет характеризоваться комбинацией из определённого брачного статуса, уровня образования, населённого пункта проживания и профессиональной группы как произведения этих вероятностей. Окончательные постстратификационные коэффициенты для каждого і-того индивида с профилем ј-тых подкатегорий (например, «военный, холостой, из посёлка городского типа, с дипломом о высшем образовании») были рассчитаны как обратные показатели к построенному индексу по формуле $\frac{1}{\Pi_{(\text {по всем } k)} p_{i j k}}$. Это даёт нам возможность придать больший вес в выборке тем наблюдениям, которые относятся к наименее объёмным группам. Окончательные объёмы выборки, а также построенные доли представлены в Приложении П4.

Также были построены модели с подключением фактора самооценки здоровья в целях проверки полученных результатов на устойчивость. Риск стать инвалидом у людей с разным уровнем самооценки здоровья оказался независимым от времени (на основе параллельности кривых «лог минус лог») и не повлиял на характер соотношений рисков стать инвалидом у представителей подгрупп в разных типах населенных пунктов с разным уровнем образования, разным семейным статусом, разных профессий. Результаты расчетов показали, что люди, оценивающие своё здоровье более высоко, в среднем имеют и более низкий риск стать инвалидом, что выглядит вполне логично. Однако во всех моделях для всех групп инвалидности, в которые была включена переменная самооценки здоровья, логарифм правдоподобия оказался ниже, чем в аналогичных моделях без него. Это может говорить о том, что модели без учёта параметра самооценки здоровья могут давать точные результаты. Видимо, сказывается ситуация, когда далеко не все респонденты, низко оценившие свое здоровье и самочувствие, имеют официальный статус инвалида.

В таблице 3 представлены результаты моделирования риска стать инвалидом в целом, а также риска стать инвалидом II или III группы.

С учётом того, что мы работаем со стратифицированной по полу моделью пропорциональных рисков, представленные в таблице коэффициенты являются общими для мужчин и женщин, а гендерные различия находят отражение в разных величинах базового риска стать инвалидом для мужчин и женщин. Все уравнения получились статистически значимыми на уровне не меньше, чем $\alpha=0,01$. Также статистически 
значимыми оказались почти все коэффициенты в моделях, за исключением коэффициентов при переменной законченного первого класса школы.

\section{Таблица 3. Результаты построения регрессии Кокса для оценки риска стать инвалидом (значение Ехр (В))}

\begin{tabular}{|c|c|c|c|c|c|c|}
\hline Переменные в уравнении & II группа & \begin{tabular}{|c|} 
II группа \\
(с учетом \\
фактора \\
«самооценка \\
здоровья») \\
\end{tabular} & III группа & \begin{tabular}{|c|} 
III группа \\
(с учетом \\
фактора \\
«самооценка \\
здоровья») \\
\end{tabular} & Все группы & $\begin{array}{c}\text { Все группы } \\
\text { (с учетом } \\
\text { фактора } \\
\text { «самооценка } \\
\text { здоровья») } \\
\end{array}$ \\
\hline \multicolumn{7}{|c|}{ Неквалифицированные рабочие всех отраслей (базовая группа) } \\
\hline Военнослужащие & 0,330 & 0,362 & 0,000 & 0,000 & 0,620 & 0,603 \\
\hline $\begin{array}{l}\text { Законодатели; крупные } \\
\text { чиновники; руководители } \\
\text { высшего и среднего звена }\end{array}$ & 0,597 & 0,615 & 0,848 & 0,706 & 0,757 & 0,747 \\
\hline $\begin{array}{l}\text { Специалисты высшего } \\
\text { уровня квалификации }\end{array}$ & 4,930 & 4,972 & 2,610 & 2,224 & 2,865 & 2,609 \\
\hline $\begin{array}{l}\text { Специалисты среднего } \\
\text { уровня квалификации; } \\
\text { чиновники }\end{array}$ & 8,484 & 8,400 & 2,767 & 2,327 & 4,384 & 4,421 \\
\hline $\begin{array}{l}\text { Служащие офисные и по } \\
\text { обслуживанию клиентов }\end{array}$ & 1,847 & 1,686 & 2,015 & 1,859 & 1,815 & 1,872 \\
\hline $\begin{array}{l}\text { Работники сферы } \\
\text { торговли и услуг }\end{array}$ & 2,019 & 1,731 & 3,818 & 2,581 & 2,436 & 1,590 \\
\hline $\begin{array}{l}\text { Квалифицированные } \\
\text { работники сельского, } \\
\text { лесного хозяйства и } \\
\text { рыбоводства }\end{array}$ & 4,926 & 5,024 & 0,000 & 0,000 & 0,850 & 0,865 \\
\hline $\begin{array}{l}\text { Квалифицированные } \\
\text { рабочие, занятые ручным } \\
\text { трудом }\end{array}$ & 1,120 & 1,077 & 1,972 & 1,636 & 1,598 & 1,416 \\
\hline $\begin{array}{l}\text { Квалифицированные } \\
\text { рабочие, использующие }\end{array}$ & 0,122 & 0,108 & 0,478 & 0,517 & 0,439 & 0,438 \\
\hline
\end{tabular}

машины и механизмы

Официально зарегистрированы, но вместе не живут (базовая группа)

\begin{tabular}{|c|c|c|c|c|c|c|}
\hline Никогда в браке не & & & & & & \\
\hline состояли & 33,428 & 35,191 & 11,812 & 14,507 & 43,814 & 51,488 \\
\hline $\begin{array}{l}\text { Состоите в } \\
\text { зарегистрированном } \\
\text { браке }\end{array}$ & 6,277 & 6,549 & 7,170 & 7,568 & 7,587 & 8,527 \\
\hline $\begin{array}{l}\text { Живете вместе, но не } \\
\text { зарегистрированы }\end{array}$ & 5,393 & 5,967 & 4,216 & 5,785 & 5,013 & 6,732 \\
\hline $\begin{array}{l}\text { Разведены и в браке не } \\
\text { состоите }\end{array}$ & 2,577 & 2,699 & 3,169 & 3,799 & 2,634 & 2,976 \\
\hline Вдовец (вдова) & 2,445 & 2,439 & 1,981 & 1,676 & 2,091 & 1,947 \\
\hline \multicolumn{7}{|l|}{ Село (базовая группа) } \\
\hline Областной центр & 2,940 & 2,725 & 2,770 & 2,210 & 3,210 & 3,051 \\
\hline Город & 4,008 & 3,866 & 2,233 & 1,912 & 2,600 & 2,463 \\
\hline ПГТ & 2,337 & 2,316 & 0,980 & 0,620 & 2,483 & 2,077 \\
\hline \multicolumn{7}{|c|}{ Законченное высшее образование и выше (базовая группа) } \\
\hline Окончил 0-6 классов & 0,091 & 0,086 & 0,922 & 0,438 & 0,670 & 0,561 \\
\hline $\begin{array}{l}\text { Незаконченное среднее } \\
\text { образование (7-8 классов) }\end{array}$ & 1,573 & 1,748 & 100,908 & 6,768 & 7,588 & 6,560 \\
\hline $\begin{array}{l}\text { Незаконченное среднее } \\
\text { образование (7-8 классов) } \\
+ \text { что-то ещё }\end{array}$ & 5,167 & 5,240 & 18,979 & 10,576 & 8,570 & 6,827 \\
\hline $\begin{array}{l}\text { Законченное среднее } \\
\text { образование }\end{array}$ & 3,399 & 3,605 & 27,226 & 19,813 & 9,617 & 8,655 \\
\hline
\end{tabular}




\begin{tabular}{|c|c|c|c|c|c|c|}
\hline Переменные в уравнении & II группа & \begin{tabular}{|c|} 
II группа \\
(с учетом \\
фактора \\
«самооценка \\
здоровья») \\
\end{tabular} & III группа & \begin{tabular}{|c|} 
III группа \\
(с учетом \\
фактора \\
«самооценка \\
здоровья») \\
\end{tabular} & Все группы & \begin{tabular}{|c|} 
Все группы \\
(с учетом \\
фактора \\
«самооценка \\
здоровья») \\
\end{tabular} \\
\hline $\begin{array}{l}\text { Законченное среднее } \\
\text { специальное образование } \\
\text { Самооценка здоровья (от }\end{array}$ & 5,283 & 5,752 & 18,217 & 14,350 & 7,698 & 7,124 \\
\hline $\begin{array}{l}1 \text { - очень плохое, до } 5 \text { - } \\
\text { очень хорошее) }\end{array}$ & & 0,557 & & 0,352 & & 0,410 \\
\hline Число наблюдений (N) & $\begin{array}{r}2554172 \\
\text { (исходно } \\
\text { было 188) }\end{array}$ & $\begin{array}{r}2553057 \\
\text { (исходно } \\
\text { было 187) }\end{array}$ & $\begin{array}{r}3469224 \\
\text { (исходно } \\
\text { было 311) }\end{array}$ & $\begin{array}{r}3464401 \\
(\text { исходно } \\
\text { было 303) }\end{array}$ & $\begin{array}{r}6805433 \\
(\text { исходно } \\
\text { было 518) }\end{array}$ & $\begin{array}{r}6799242 \\
\text { (исходно } \\
\text { было 508) }\end{array}$ \\
\hline -2 Log-правдоподобие & 87829159,41 & 87648041,43 & 118132192,8 & 116901845,5 & 225954754,1 & 224313687,6 \\
\hline Хи-квадрат & 33069275,02 & 33125144,39 & 11386194,98 & 12167498,11 & 40215612,9 & 42660673,87 \\
\hline Число степеней свободы & 22 & 23 & 22 & 23 & 22 & 23 \\
\hline Значимость уравнения & 0,000 & 0,000 & 0,000 & 0,000 & 0,000 & 0,000 \\
\hline
\end{tabular}

Источник: Расчеты авторов.

Примечание: Все коэффициенты Вальда, на основе которых проверяли гипотезы о значимости коэффициентов уравнения, значимы на 1\%-ном уровне.

Функции кумулятивного риска позволяют сформулировать основные выводы из проведённого анализа².

Функция риска представляет собой вероятность того, что респондент, не имевший инвалидности за $\mathrm{t}$ предшествующих лет жизни, станет инвалидом в текущем возрасте Т исполнившихся лет, и задаётся следующей формулой:

$$
\lambda(t)=\lim _{\Delta \rightarrow 0} \frac{P(t<T \leq t+\Delta \mid T>t)}{\Delta} .
$$

Функция кумулятивного риска представляет собой накопленную сумму вероятностей перехода в состояние инвалидности к каждому возрасту в исполнившихся годах, до которого человек дожил, не переходя в состояние инвалидности.

При построении графиков функций кумулятивного риска выборка была разбита на две подвыборки по полу, функции рисков считались отдельно для каждой из них следующим образом:

1. оценивали кумулятивную функцию выживаемости для каждого из полов (уравнение Каплана-Мейера):

$$
S_{j}(t)=\prod_{i \leq t}\left(1-\frac{d_{i j}}{n_{i j}}\right)
$$

где $n_{i j}$ - число индивидов пола j, для которых инвалидность ещё не наступила к моменту $\mathrm{i}$, a $d_{i j}$ - число индивидов пола $\mathrm{j}$, для которых инвалидность уже наступила к моменту i.

\footnotetext{
${ }^{2}$ В силу ограниченности объёма, мы приводим только функции риска стать инвалидом II группы, для других групп они строятся аналогичным образом. 
Кумулятивная вероятность остаться здоровым рассчитывается путём перемножения вероятностей остаться здоровым в одном возрастном интервале на вероятность остаться здоровым в следующем, вплоть до возраста t.

2. через соотношение $H_{j}(t)=-\log \left(S_{j}(t)\right)$ находили функцию кумулятивного риска для пола ј к каждому возрасту $\mathrm{t}$.

Расчеты подтвердили весьма значительные различия в вероятности риска стать инвалидом II группы в разрезе пола.

Наиболее заметно риск инвалидности растет для мужчин и для женщин после 50 летнего возраста и к возрасту 60 лет достигает 3-4\% (рисунок 2). Резкий рост происходит у женщин после 70 лет, у мужчин - после 75 лет. Подобная динамика в большей степени обусловлена не только состоянием здоровья, но и ориентацией на получение социальных льгот, связанных со статусом инвалидности. С каждым новым прожитым годом жизни шансы средней женщины в возрасте старше 27 лет остаться здоровой (не стать инвалидом II группы) сокращаются более быстрыми темпами, чем среднего мужчины из той же возрастной группы. Можно предположить, что такая ситуация обусловлена как раз большим вниманием женщин к своему здоровью, контролю имеющихся хронических заболеваний, поиском информации о возможности получения социальных льгот, компенсирующих потери здоровья.

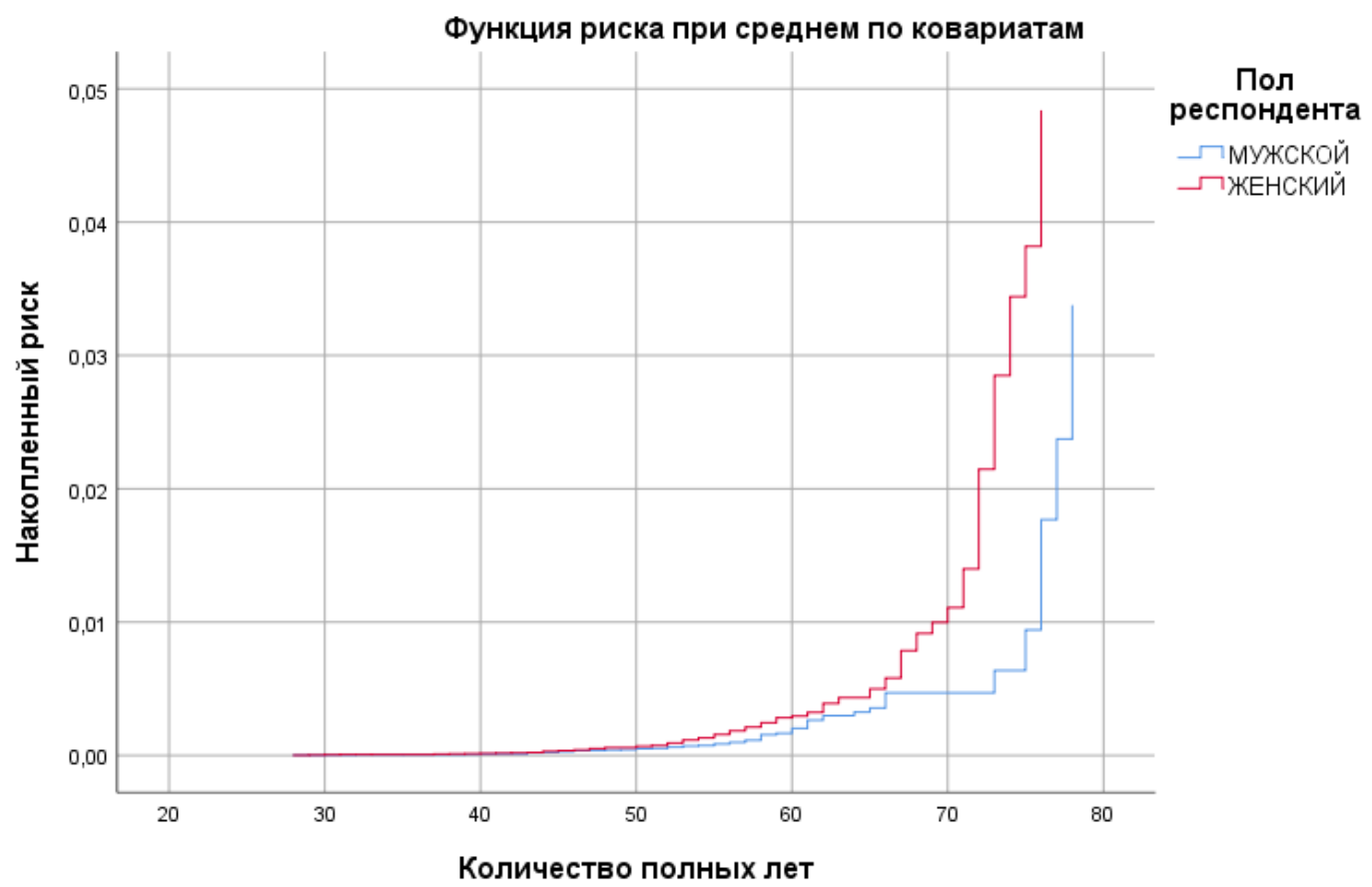

Рисунок 2. Повозрастная динамика кумулятивного риска стать инвалидом II группы в гендерном разрезе

По итогам моделирования можно сделать следующие выводы относительно факторов, влияющих на риск инвалидности. 
Риск стать инвалидом как в целом, так и II или III группы наиболее высок у никогда не состоящих в браке. С одной стороны, здесь можно сделать вывод о благоприятном влиянии на состояние здоровья и профилактику инвалидности семейного образа жизни, заботы близких людей, большем психологическом благополучии, если бы не одно «но». Риск инвалидности для лиц, состоящих в браке, выше, чем для тех, чей брак распался вследствие развода или овдовения. Графики возрастной динамики кумулятивного риска в разрезе семейного (брачного) статуса для мужчин и женщин позволяют заметить, что значительная дифференциация риска стать инвалидом в зависимости от брачного состояния характерна только для женщин. При сохранении наиболее значительного риска стать инвалидом II группы, особенно резко возрастающего после 60 лет, характерны наименьшие значения риска для тех женщин, чей брак уже распался.

У мужчин, при сохраняющемся большом риске стать инвалидом для никогда не состоявших в браке, причем гораздо меньшем, чем для женщин, такая дифференциация не наблюдается (рисунки 3,4 ). Можно предположить, что на высоком риске инвалидности для не состоящих в браке сказываются особенности образа жизни, большая склонность к вредным привычкам. Однако можно выдвинуть и другую гипотезу: лица, имеющие серьезные проблемы со здоровьем, изначально «не пользуются спросом» на брачном рынке, имеют меньше шансов создать семью, с возрастом у них выше шансы получить статус инвалида.

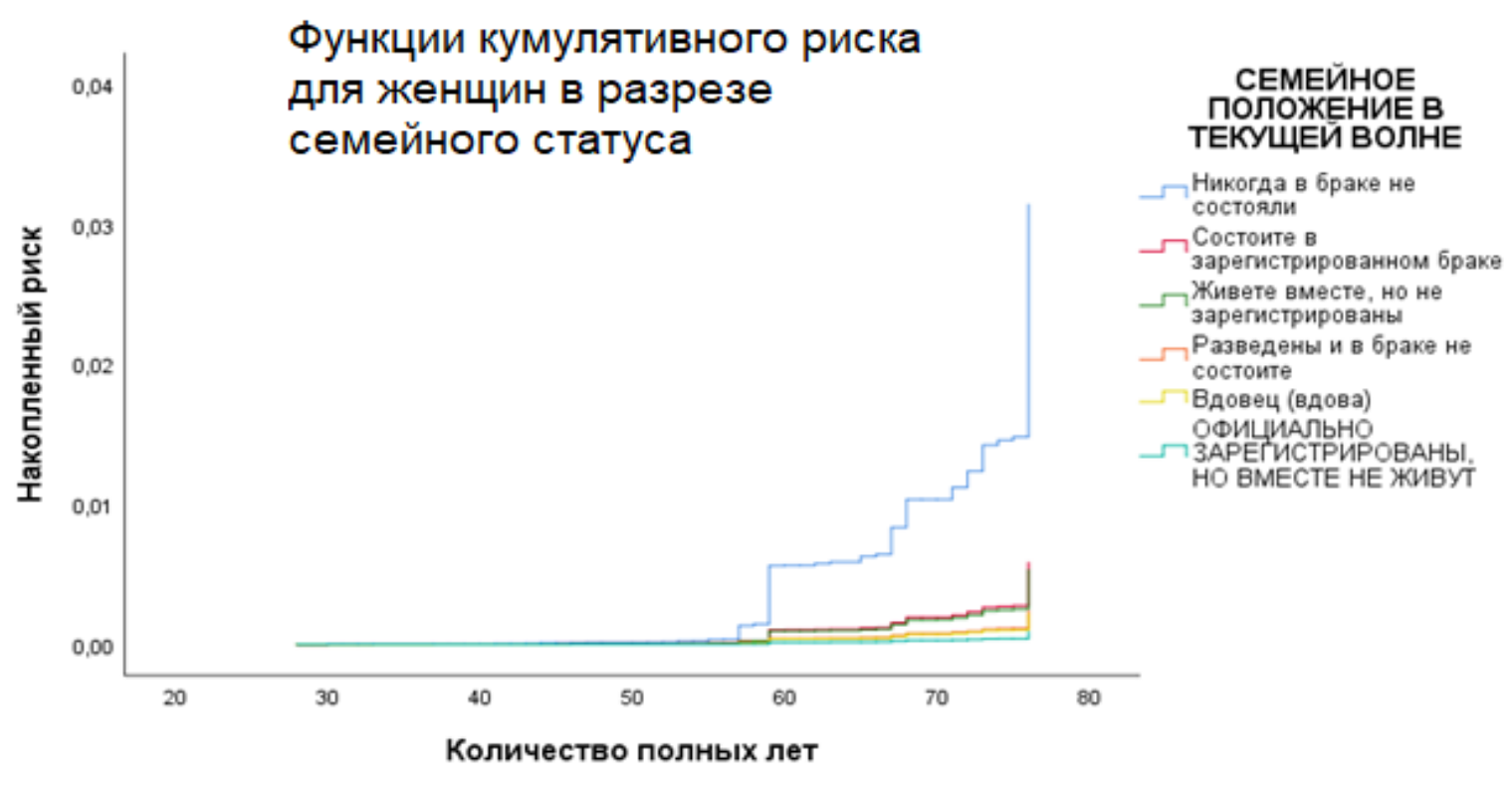

Наблюдения, взвешенные по WEIG2

Рисунок 3. Возрастная динамика кумулятивного риска стать инвалидом II группы в разрезе семейного статуса, женщины

Источник: Построено авторами в программном пакете IBM SPSS.

Примечание: Построено на укрупнённых группах наблюдений. 


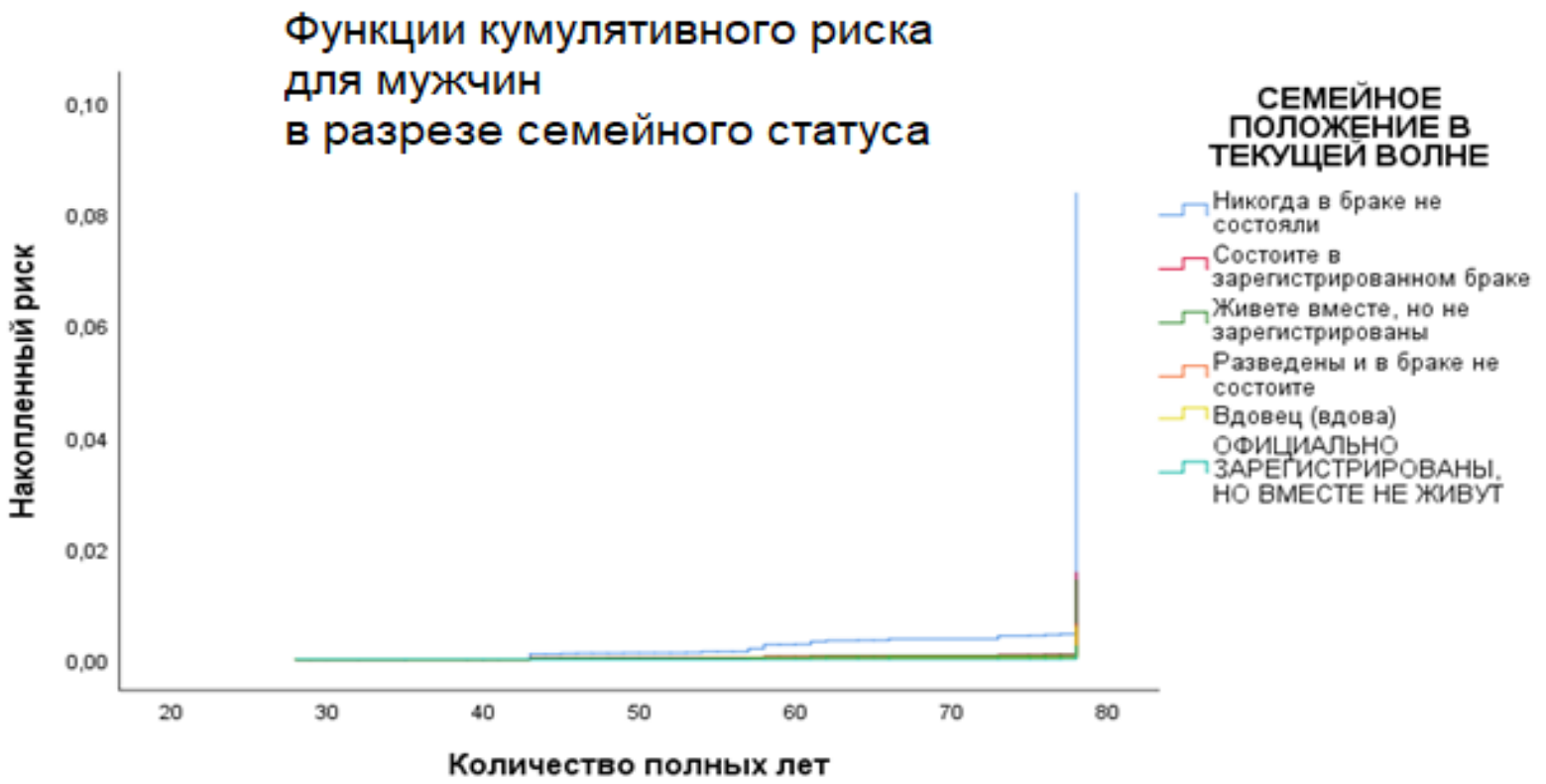

\section{Рисунок 4. Возрастная динамика кумулятивного риска стать инвалидом II группы в разрезе семейного статуса, мужчины}

Источник: Построено авторами в программном пакете IBM SPSS.

Примечание: Построено на укрупнённых группах наблюдений.

Выявленные гендерные различия в риске стать инвалидом в зависимости от брачного статуса подтверждают результаты исследований, свидетельствующие о значительной перегрузке работающих женщин, имеющих семью и детей (Калабихина, Шайкенова 2019). В России сохраняются значительные гендерные различия в бюджетах времени, значительная часть семей придерживалась и придерживается традиционного распределения домашних обязанностей. Выполнение обязанностей по воспитанию детей, уходу за близкими и домашним хозяйством в сочетании с профессиональной деятельностью приводит к физическим и психологическим перегрузкам, не оставляет времени на заботу о своем здоровье.

В некоторых группах работников риск стать инвалидом значимо выше, чем у остальных. Исследования показывают, что здоровье индивида - это результат взаимодействия целого ряда факторов, охватывающих и естественные процессы старения, и различного рода социальные обстоятельства (Русинова 2019).

Анализ влияния профессиональной группы на риск стать инвалидом позволил сформулировать следующие предварительные выводы. Наиболее высокий риск стать инвалидом имеют: 1) специалисты высшего уровня квалификации; 2) специалисты среднего уровня квалификации и чиновники; 3) офисные служащие и специалисты по обслуживанию клиентов; 4) работники сферы торговли и услуг.

Более низкий риск стать инвалидом имеют: 1) военнослужащие; 2) квалифицированные работники, использующие машины и механизмы; 3) законодатели, крупные чиновники и руководители высшего и среднего звена. 
Неоднозначное отличие в риске стать инвалидом имеют: 1) квалифицированные работники сельского, лесного хозяйства и рыбоводства (значимо более высокий риск стать инвалидом II группы и в целом, значимо более низкий - III группы); 2) квалифицированные работники, занятые ручным трудом (значимо более высокий риск стать инвалидом III группы и в целом, значимо более низкий - II группы).

Однако некоторые предположения можно высказать и на основе уже полученных результатов, хотя сложно определить однозначные очертания профилей высокорисковых и низкорисковых работников с точки зрения получения инвалидности. С одной стороны, мы видим, что более высокий риск стать инвалидом наблюдается у представителей профессий, подразумевающих частое общение с людьми, ответственность за принятие решений, наличие стрессовых ситуаций на работе. Выпадают из этого перечня «законодатели, крупные чиновники и руководители высшего и среднего звена». С другой стороны, высокий риск стать инвалидом II группы у работников сельского хозяйства, видимо, обусловлен тяжелыми условиями труда. Кроме того, сказываются особенности образа жизни в целом: зачастую вдали от семьи, отсутствие регулярного (подчас и качественного) питания, употребление алкоголя и табака, сложности с доступом к медицинской помощи.

Среди остальных профессиональных групп повышенным риском инвалидности выделяются специалисты высшего уровня квалификации. Видимо, помимо занятости в условиях стресса и недостаточной физической активности, сказывается следующий факт. Учет численности инвалидов в России построен на обращаемости граждан в учреждения МСЭ. Исследователи отмечают, что обращаемость зависит от доступности соответствующих услуг, прежде всего лечебных учреждений и медико-социальной экспертизы, а также информированности населения о вопросах здоровья и социального обеспечения (Бурдяк, Тындик 2016). Категория специалистов в большей степени информирована о проблемах здоровья и возможностях здравоохранения, особенностях и перспективах получения статуса инвалида.

Отсутствие информации в программе обследования о заболевании, повлекшем наступление инвалидности, затрудняет уточнение причин различий в рисках стать инвалидом у представителей разных профессиональных групп. Полученный разброс показателей не позволяет дать однозначные оценки и приводит к мысли о необходимости проведения более детального анализа с учетом возрастных характеристик представителей каждой из профессиональных групп и оценки условий труда.

Гендерные различия сохраняются и в величине риска стать инвалидом в зависимости от различных признаков, в частности профессиональной группы. И позволяют дать некоторые уточнения.

Для женщин характерен резкий подъем и дальнейший интенсивный рост показателя после 60 лет, особенно для таких профессиональных категорий, как специалисты высшего и среднего уровня квалификации (чиновники) и квалифицированные работники сельского хозяйства. 
У мужчин наблюдается гораздо более плавная динамика показателя. И хотя повышенный риск инвалидности наблюдается для тех же профессиональных групп, его динамика с возрастом мало меняется.

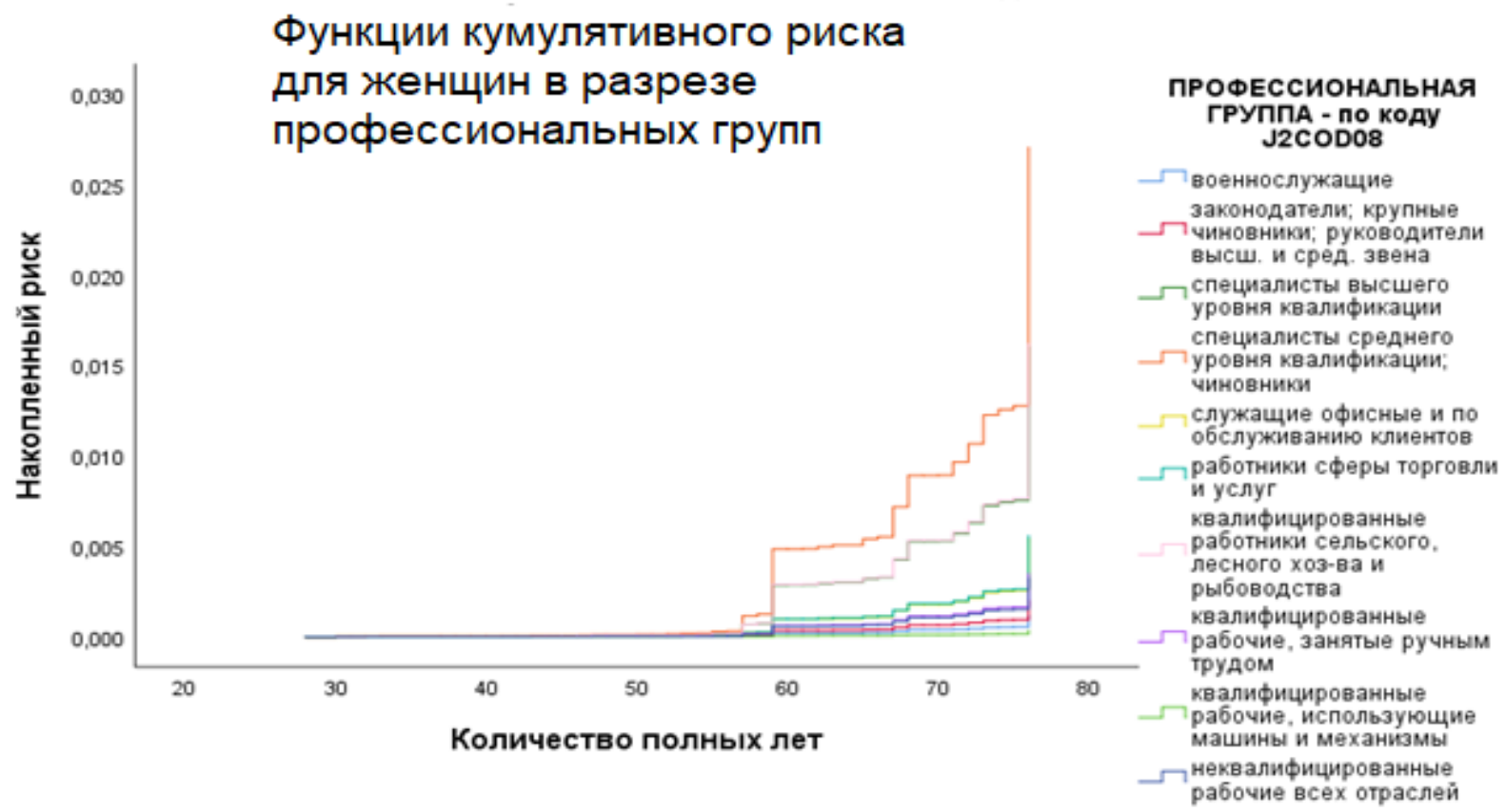

\section{Рисунок 5. Возрастная динамика кумулятивного риска стать инвалидом II группы в разрезе профессиональных групп, женщины}

Источник: Построено авторами в программном пакете IBM SPSS на основе данных РМЭ3 2003-2018.

Примечание: Построено на укрупнённых группах наблюдений.

Лица с более низким уровнем образования имеют более высокий риск получения инвалидности. Причем для отдельных уровней образования проявляются различия в риске получить II или III группы инвалидности. Наибольший риск стать инвалидом имеют жители городов. За исключением жителей посёлков городского типа в модели риска стать инвалидом III группы, жители сельской местности имеют наименьший риск получить инвалидность. Можно предположить, что, наряду с возможно более благоприятной экологической ситуацией, здесь играет роль доступность (скорее, недоступность) системы медицинских услуг и медико-социальной экспертизы.

Для обоих полов шансы жителей сельских поселений и малых городов остаться здоровыми с каждым годом жизни сокращаются медленнее, чем для жителей городов. Данную особенность можно объяснить сравнительной недоступностью медицинских услуг и учреждений, недостаточным знакомством с правилами и возможностями установления инвалидности, что сказывается на риске инвалидности и для отдельных профессиональных групп. 


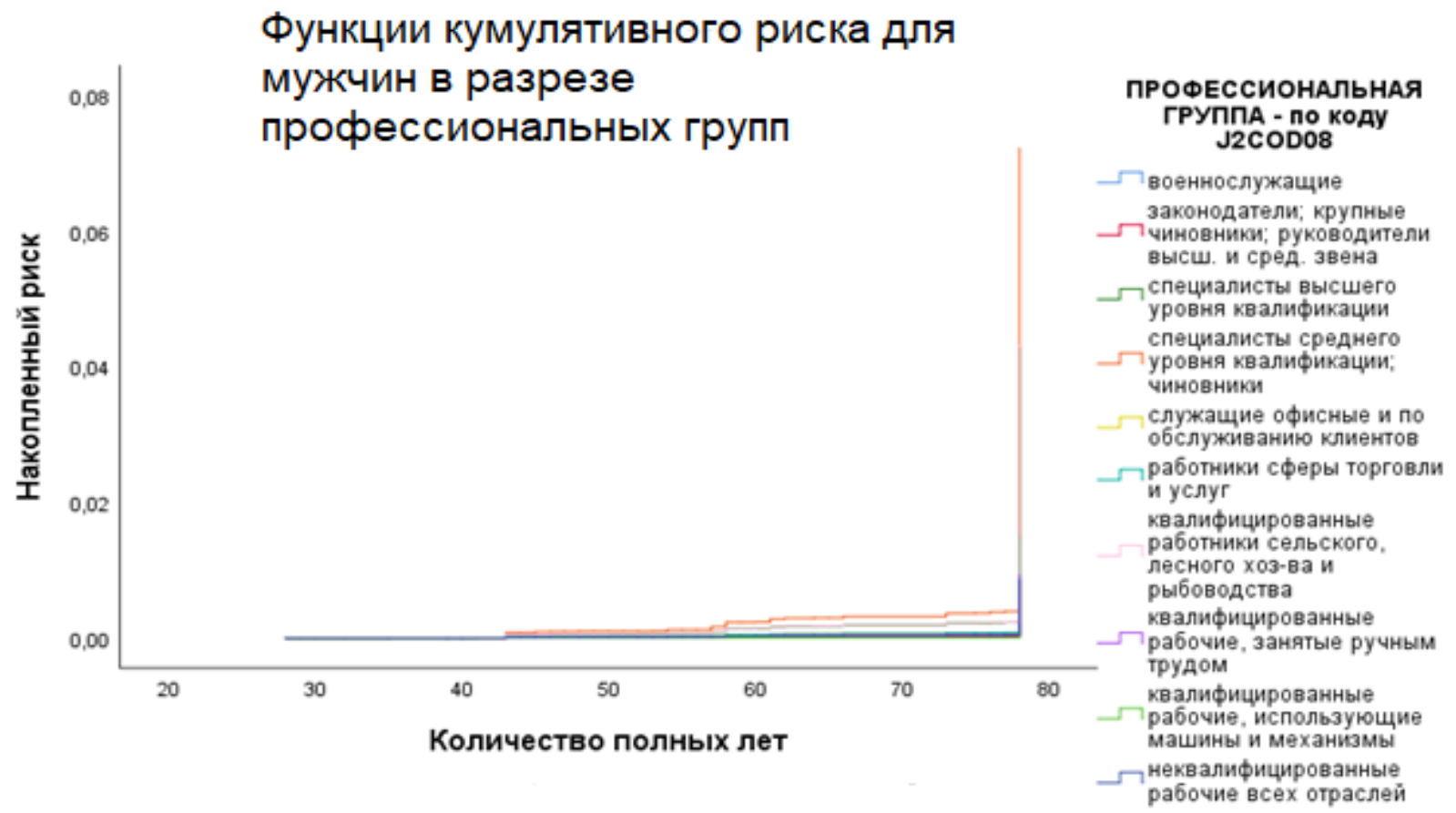

Рисунок 6. Возрастная динамика кумулятивного риска стать инвалидом II группы в разрезе профессиональных групп, мужчины

Источник: Построено авторами в программном пакете IBM SPSS на основе данных РМЭ3 2013-2018.

Примечание: Построено на укрупнённых группах наблюдений.

В целом мы можем судить, что за полученными результатами в различиях риска инвалидности для лиц разных социальных групп могут стоять как более физически и морально изнуряющие условия труда у отдельных категорий работников, особенности образа жизни, что и создаёт для них более высокий риск стать инвалидом, так и доступность медицинских услуг и информированность о процедуре назначения инвалидности и предоставляемых льготах. Результаты моделирования в определенной степени являются подтверждением формирования неравенства в здоровье и, как следствие, различий в риске инвалидности под влиянием совокупности факторов (экономических (Lynch et al., 2000; Mackenbach, deJong 2018), психосоциальных (Adler, Snibbe 2003; Marmot 2004), культурологических (Brunello et al. 2016).

\section{Выводы}

Проведенное исследование подводит к выводу, что в целях предупреждения потерь человеческого капитала страны в результате инвалидизации следует предпринять меры по созданию более безопасных условий труда (например, для работодателей - в виде стимулирующих надбавок за соблюдение необходимого уровня безопасности и гигиены труда их подчинённых в размере, пропорциональном чистой общественной выгоде от предотвращённых потерь национального человеческого капитала). 
Формально риск получения статуса инвалида начинает нарастать в довольно зрелых, пожилых возрастах, когда, по сути, профессиональная деятельность человека уже заканчивается. Однако получение инвалидности в пожилом возрасте обусловлено накопленными дефектами здоровья, в значительной части случаев, как показало проведенное моделирование, связанными с профессиональной деятельностью. При анализе формирования контингентов лиц с инвалидностью, помимо факторов инвалидности во взрослом возрасте, необходимо также принимать во внимание рост детской инвалидности в России, который в будущем может привести к увеличению масштаба инвалидности и в трудоспособных возрастах.

Выявление более точных каналов получения инвалидности (например, идёт ли речь о систематическом подрыве психического здоровья или же о повышенном риске получить травму от внешних причин, связанных с профессиональной деятельностью и др.) требует более углублённого дополнительного исследования.

Важный итог исследования - значительные гендерные различия в риске инвалидности, в том числе с учетом профессионального и брачного статуса.

Результаты исследования наводят на размышления о сути индикатора «наличие официального статуса инвалида». Данная характеристика скорее служит не показателем здоровья индивида, а индикатором доступности медицинских услуг и услуг медикосоциальной экспертизы. С одной стороны, на макроуровне с точки зрения потерь и затрат государства, связанных с распространенностью инвалидности, данный подход не лишен смысла. Но с точки зрения личных потерь здоровья, выстраивания эффективной стратегии самосохранительного поведения важно формирование интегрального показателя результирующей переменной при оценке факторов потерь здоровья. Порой противоречивые выводы, полученные в ходе моделирования, приводят к необходимости проведения многомерных группировок для выявления однородных групп россиян с точки зрения социально-демографических, профессиональных характеристик и стратегий самосохранительного поведения.

Проведенное моделирование показало возможность определения риска инвалидности для россиян на основе данных лонгитюдных исследований. Однако масштабы выборки не позволили рассчитать риск смерти для лиц с инвалидностью. В настоящее время в открытом доступе отсутствуют данные официальной статистики или обследований, позволяющих сделать такие расчеты. Анализ выявил проблемы российской информационной базы статистики инвалидности, не позволяющей проводить детальный анализ риска инвалидности и смертности инвалидов. Мировой опыт свидетельствует о возможности использования для оценки ситуации в сфере инвалидности данных переписей населения (Рамонов, Пьянкова 2014), что пока не нашло применения в России. Ряд гипотез, которые сформировались у авторов на этапе обсуждения результатов моделирования, нет возможности проверить на основе имеющихся данных. Программы проводимых в последние годы Росстатом выборочных обследований населения при условии формирования соответствующей представительной выборки (в частности, с учетом возможностей Федерального реестра инвалидов) позволили бы получить детальное представление о масштабах инвалидности, различных аспектах жизнедеятельности 
инвалидов. Обращение к теме выборочных обследований в ходе анализа положения инвалидов обусловлено не только необходимостью получения ряда качественных оценок, характеризующих положение инвалидов в обществе, но и дает возможность выявить факторы, влияющие на риск инвалидности, определить перспективы процесса инвалидизации общества (особенно в случае мониторинговых исследований). В частности, необходимость проводить опросы целевых групп в контексте оценки проблем инвалидности отмечена в «Руководящих указаниях и принципах разработки статистических данных по проблеме инвалидности $(\mathrm{OOH}) »($ Организация объединенных наций 2001). В настоящее время в России отсутствуют масштабные государственные обследования условий жизнедеятельности инвалидов и в домохозяйствах, и в стационарных учреждениях, предназначенных для проживания инвалидов.

\section{ЛИТЕРАТУРА}

Бурдяк А.Я., Тындик А.О. (2016). Измерение инвалидности и положение инвалидов: российский и международный подходы. Вестник НГУЭУ, 1, 22-43.

Васин С.А. (2017) Перспективы изменения численности и возрастного состава взрослых инвалидов в России. Проблемы прогнозирования. 5, 129-139.

Владимирова О.Н., Башкирева А.С., Коробов М.В., Ломоносова О.В., Хорькова О.В. (2017). Современные тенденции общей инвалидности на фоне постарения населения в РФ. Клиническая геронтология, 5-6, 44-50.

Всемирная организация здравоохранения (2011). Всемирный доклад по инвалидности. URL: http://www.who.int/disabilities/world_report/2011/summary_ru.pdf.

Всемирная организация здравоохранения (2020). Десять фактов об инвалидности. URL: https://www.who.int/features/factfiles/disability/ru/

Вяльшина А.А. (2020). Влияние уровня образования на состояние здоровья сельского населения. Социальные аспекты здоровья населения, 1(66). DOI: 10.21045/2071-50212020-66-1-6

Демьянова А.В., Лукьянова А.Л. (2017). Низкий уровень занятости инвалидов в России результат дискриминации? Экономический журнал ВШЭ, 21 (3), 385-411.

Демьянова А.В., Лукьянова А.Л. (2016). Влияние статуса инвалида на предложение труда в России. Прикладная эконометрика, (44), 50-74.

Иванова А.Е., Лопаков К.В., Землянова Е.В., Михайлов А.Ю. (2019). Социальный контекст ограничений жизнедеятельности и инвалидности в России. Социальныле аспекты здоровья населения, 1(65). DOI: https://dx.doi.org/10.21045/2071-5021-2019-65$1-1$

Инвалиды в России: причины и динамика инвалидности, противоречия и перспективы социальной политики (1999) / [Т. М. Малева, С. А. Васин, О. Ю. Голодец, С. В. Бесфамильная]; Бюро экон. анализа. - Москва: РОССПЭН.

Калабихина И.Е., Шайкенова Ж.К. (2019). Затраты времени на домашнюю работу: детерминанты гендерного неравенства. Мониторинг общественного мнения: экономические и сочиальные перемены, 3, 261-285. 
Кулагина Е.В. (2016). Демографические факторы инвалидности: ориентиры для государственного регулирования и статистики. В Герасимов В.И., Ефременко Д.В. (Ред.), Россия: тенденщии и перспективы развития. Ежегодник (сс. 502-506). М.: РАН. ИНИОН.

Кучмаева О.В. (2020). Занятость инвалидов в регионах России: состояние, дифференциация, факторы. Статистика и Экономика, 17(5), 27-37. https://doi.org/10.21686/2500-3925-2020-5-27-37

Макаренцева А.О., Васин С.А., Хасанова Р.Р. (2016) Как оценить число инвалидов в России // Демоскоп Weekly. 695-696. URL: http://demoscope.ru/weekly/2016/0695/tema01.php

Малева Т.М. (Ред.) (2017). Инвалидность и сочиальное положение инвалидов в России. Москва: Издательский дом «Дело» РАНХиГС.

Мешков Н.А., Бухтияров И.В., Вальцева Е.А. (2020). Оценка факторов риска профессиональной деятельности и состояние здоровья сотрудников противопожарной службы. Медицина труда и промышленная экология, 60(10), 658-673. https://doi.org/10.31089/1026-9428-2020-60-10-658-673

Нацун Л.Н., Шабунова А.А. (2018). К вопросу об экономической цене инвалидности. Экономические и социальные перемены: факты, тенденции, прогноз, 11(2), 160-174. DOI: $10.15838 /$ esc.2018.2.56.11

НИУ Высшая школа экономики (2020). Российский мониторинг экономического положения и здоровья населения НИУ-ВШЭ (RLMS-HSE). Объединенная база данных 1994-2018. Домохозяйства; Индивиды. Волны 12-27. URL: http://www.cpc.unc.edu/projects/rlms; URL: http://www.hse.ru/rlms (данные загружены 01.02.2020).

Организация объединенных наций (2001). Руководящчие указания и принцุипы разработки статистических данных по проблеме инвалидности. URL: https://documents-ddsny.un.org/doc/UNDOC/GEN/N02/486/09/PDF/N0248609.pdf?OpenElement

Рамонов А.В. (2015). Интегральные показатели демографических потерь от смертности и травматизма в результате дорожно-транспортных происшествий в России. Демографическое обозрение, 2(4), 136-149. https://doi.org/10.17323/demreview.v2i4.1771

Рамонов А.В., Пьянкова А.И. (2014). Изучение здоровья: потенциал переписей населения. Демографическое обозрение, 1(2), 140-

155. https://doi.org/10.17323/demreview.v1i2.1820

Росстат (2016). Данные Комплексного обследования условий жизни населения. 2016. URL: https://rosstat.gov.ru/free_doc/new_site/KOUZ16/index.html

Росстат (2018). Данные Комплексного обследования условий жизни населения. 2018. URL: https://rosstat.gov.ru/free_doc/new_site/KOUZ18/index.html

Росстат (2020). Положение инвалидов. URL: https://rosstat.gov.ru/storage/mediabank/1-1.doc 13

Русинова Н.Л. (2019). Социальные неравенства в здоровье: посредническая роль материальных лишений и психологических ресурсов. Демографическое обозрение, 6(3), 6-30. https://doi.org/10.17323/demreview.v6i3.9853 
Adler N.E., Snibbe A.C. (2003). The role of psychosocial processes in explaining the gradient between socioeconomic status and health. Current Directions in Psychological Science, 12(4), 119-123. DOI: 10.1111/1467-8721.01245

Andersen P.K., Borch-Johnsen K., Deckert T., Green A., Hougaard P., Keiding N., Kreiner S. (1985). A Cox Regression Model for the Relative Mortality and Its Application to Diabetes Mellitus Survival Data. Biometrics, 41(4), 921. DOI: 10.2307/2530964

Bellera C.A., MacGrogan G., Debled M., de Lara C.T., Brouste V., Mathoulin-Pélissier S. (2010). Variables with time-varying effects and the Cox model: some statistical concepts illustrated with a prognostic factor study in breast cancer. BMC Med Res Methodol. Mar 16;10:20. DOI: 10.1186/1471-2288-10-20. PMID: 20233435; PMCID: PMC2846954

Brandström A., Broström G., Persson L.-A. (1984). The impact of feeding patterns on infant mortality in a nineteenth-century Swedish parish. J. Trop. Pediat, 40, 154-159. DOI: 10.1093/tropej/30.3.154

Broström G. (1987). The influence of mother's mortality on infant mortality: A case study in matched data survival analysis, Scandinavian Journal of Statistics, 14, 113-123. URL: https://www.jstor.org/stable/4616055

Brunello G., Fort M., Schneeweis N., Winter-Ebmer R. (2016). The causal effect of education on health: what is the role of health behaviors? Health Economics, 25(3), 314-336. DOI: 10.1002/hec. 3141

Cleves M.A., Gould W.W., Gutierrez R.G. Marchenko Y.V. (2010). An Introduction to Survival Analysis Using Stata. 3rd ed. College Station, TX: Stata Press.

Cortese G., Scheike T.H, Martinussen T. (2010) Flexible survival regression modelling. Stat Methods Med Res. Feb; 19(1), 5-28. DOI: 10.1177/0962280209105022. Epub 2009 Jul 16. PMID: 19608605.

Cox D.R. (1972). Regression models and life tables (with discussion). Journal of the Royal Statistical Society, Series B (Methodological), 34, 187-220. URL: http://links.jstor.org/sici?sici=00359246\%281972\%2934\%3A2\%3C187\%3ARMAL\%3E2.0.CO\%3B2-6

Cutler D.M., Lleras-Muney A. (2010). The Education Gradient in Old Age Disability. In Wise D.A. (Ed.), Research Findings in the Economics of Aging (pp. 101-120). The University of Chicago Press. URL: http://www.nber.org/chapters/c8194

Heiland E.G., Welmer A., Wang R., Santoni G., Fratiglioni L. (2019). Cardiovascular Risk Factors and the Risk of Disability in Older Adults: Variation by Age and Functional Status. Journal of the American Medical Directors Association, 20(2), 208-212.

Helgadóttir B., Narusyte J., Ropponen A., Bergström G., Mather L., Blom V., Svedberg P. (2019). The role of occupational class on the association between sickness absence and disability pension: A Swedish register-based twin study. Scandinavian Journal of Work Environment and Health, 45(6), 622-630. DOI: 10.5271/sjweh.3816

Högberg U., Wall S., Broström G. (1986). The impact of early medical technology on maternal mortality in late 19th century Sweden. International Journal of Gynecology \& Obstetrics, 24(4), 251-261. https://doi.org/10.1016/0020-7292(86)90081-0 22

Leineweber C., Marklund S., Aronsson G., Gustavsson K. (2019). Work-related psychosocial risk factors and risk of disability pension among employees in health and personal care: 
A prospective cohort study. International Journal of Nursing Studies, 93, 12-20. https://doi.org/10.1016/j.ijnurstu.2018.10.009

Lynch J.W., Smith G.D., Kaplan G.A., House J.S. (2000). Income inequality and mortality: importance to health of individual income, psychosocial environment, or material conditions. British Medical Journal, 320(7243), 1200-1204. DOI: 10.1136/bmj.320.7243.1200

Mackenbach J., de Jong J.P. (2018). Health Inequalities: an Interdisciplinary Exploration of Socioeconomic Position, Health and Causality. Amsterdam: FEAM/ALLEA Committee on Health Inequalities. Symposium Report. URL: https://www.allea.org/wpcontent/uploads/2018/11/Health_Inequalities_Symposium_Report.pdf

Marmot M.G. (2004). The status syndrome. How social standing affects our health and longevity. New York: Henry Holt \& Company

McGregor D., Palarea-Albaladejo J., Dall P., Hron K., Chastin S. (2019). Cox regression survival analysis with compositional covariates: Application to modelling mortality risk from 24-h physical activity patterns. Statistical Methods in Medical Research, 29(5), 1447-1465. https://doi.org/10.1177/0962280219864125 26

Ropponen A., Svedberg P. (2019). Risk factors of disability pensions - what will twin studies from Finland and Sweden add? European Journal of Public Health, V.29, Iss. Supplement 4, https://doi.org/10.1093/eurpub/ckz185.697 


\section{ПРИЛОЖЕНИЕ}

\section{П1. Обоснование выбора типа модели рисков с учётом проверки гипотезы пропорциональных рисков}

C учётом ресурсных возможностей пакета SPSS для проверки гипотезы традиционно применяются 2 способа (Bellera et al. 2010): 1) оценка значимости индикатора времени вида «фактор*время»; 2) построение функций вида «лог минус лог».

В первом случае потенциально могла бы проводиться оценка значимости построенных индикаторов времени вида $Z_{i j k} *\left(\ln \left(t_{i j k}\right)-\overline{\ln (t)}\right)$, где $Z_{i j k^{-}}$данная ковариата, характеризующая принадлежность $\mathrm{i}$-го индивида к j-той подгруппе k-той группы; $\overline{\ln (t)}$ - нормировочный коэффициент, представляющий собой усреднённое по наблюдениям среднее время пребывания респондента в состоянии без инвалидности. Из значимости индикаторов следует, что ковариаты зависят от времени, следовательно, необходимо строить регрессии Кокса с ковариатами, зависящими от времени. Однако категориальные ковариаты представлены более чем двумя альтернативными состояниями (например, профессиональные группы не исчерпываются двумя категориями), поэтому требуется тестирование коэффициентов при параметрах зависимости ковариат от времени на совместное равенство нулю, но для регрессии Кокса такие статистические тесты не предусмотрены. В связи с этим мы решили ограничиться вторым способом тестирования предпосылки о пропорциональности рисков.

Второй способ предполагает построение функций вида $\ln \left(-\ln \left(\right.\right.$ survival_$\left.Z_{i j k t}\right)$, где survival_$Z_{i j k t}$ - накопленное значение функции выживания для регрессора $Z_{i j k t}$ в возрасте $\mathrm{t}$ исполнившихся лет. Отметим, что $\ln \left(-\ln \left(\right.\right.$ survival_$\left.Z_{i j k t}\right)-$ монотонно неубывающая функция, которая может принимать значения на всей области действительных чисел. Тестирование гипотезы пропорциональности рисков при помощи функций «лог минус лог» устроено таким образом, что если графики функций $\ln \left(-\ln \left(\right.\right.$ survival $\left._{Z_{i j k t}}\right)$ параллельны для всех категорий из однородной группы, это говорит о независимости ковариат от времени. Например, кривые для всех профессиональных групп с возрастом параллельны друг другу, это говорит о том, что с течением времени пропорции стать инвалидом между представителями разных профессиональных групп не меняются. Построенные кривые вида «лог минус лог» демонстрируют неизменность пропорций рисков стать инвалидом с течением времени. Ниже представлено соотношение таких кривых на примере профессиональных групп в разрезе полов и риска стать инвалидом II группы (рисунки П1.1, П1.2). Аналогичные результаты получились для всех остальных категорий в моделях с инвалидами других групп. 


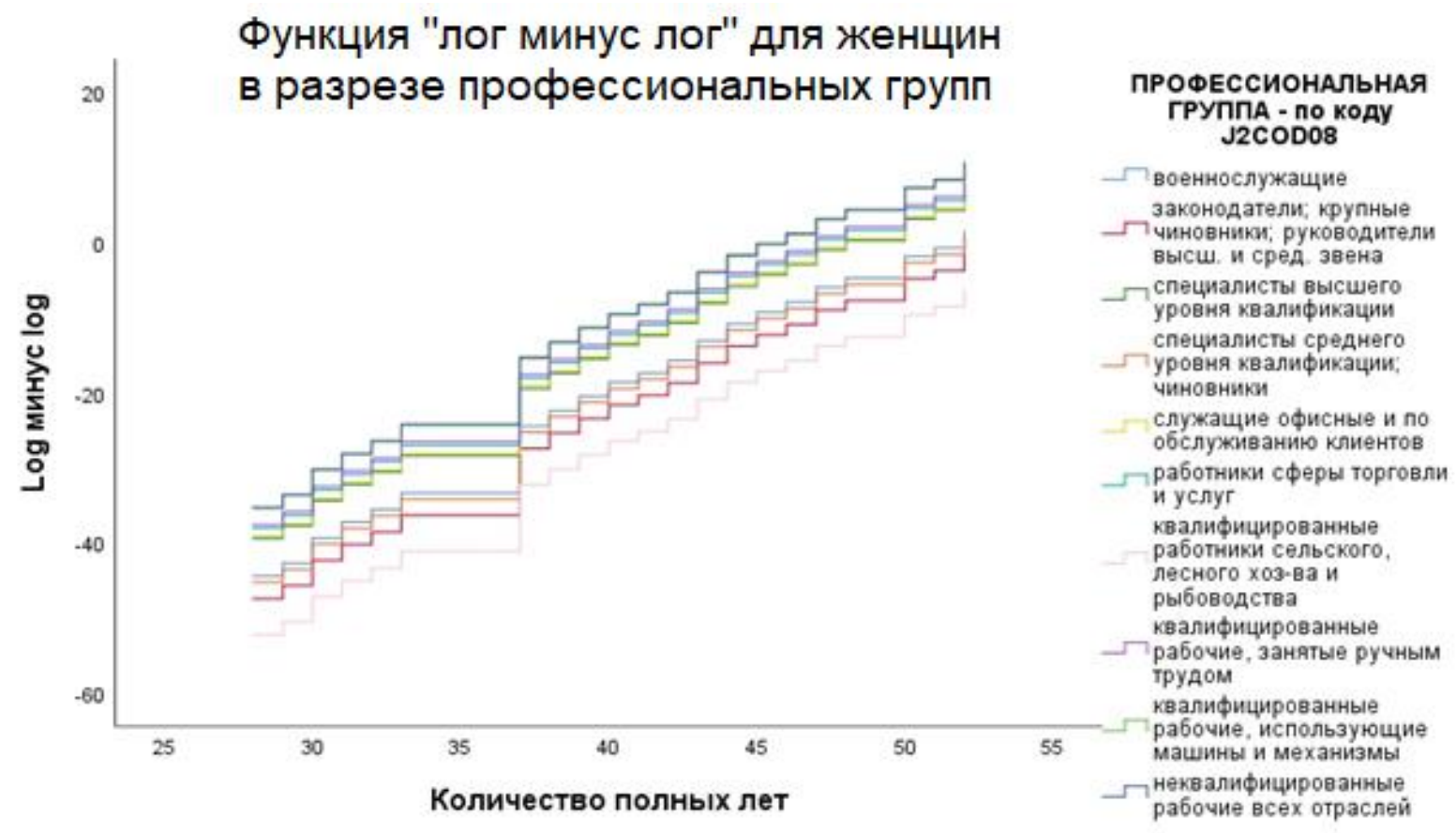

Рисунок П1.1. График «лог минус лог» в разрезе профессиональных групп, женская подвыборка

Источник: Построено авторами в программном пакете IBM SPSS.

Примечание: Построено на укрупнённых группах наблюдений.

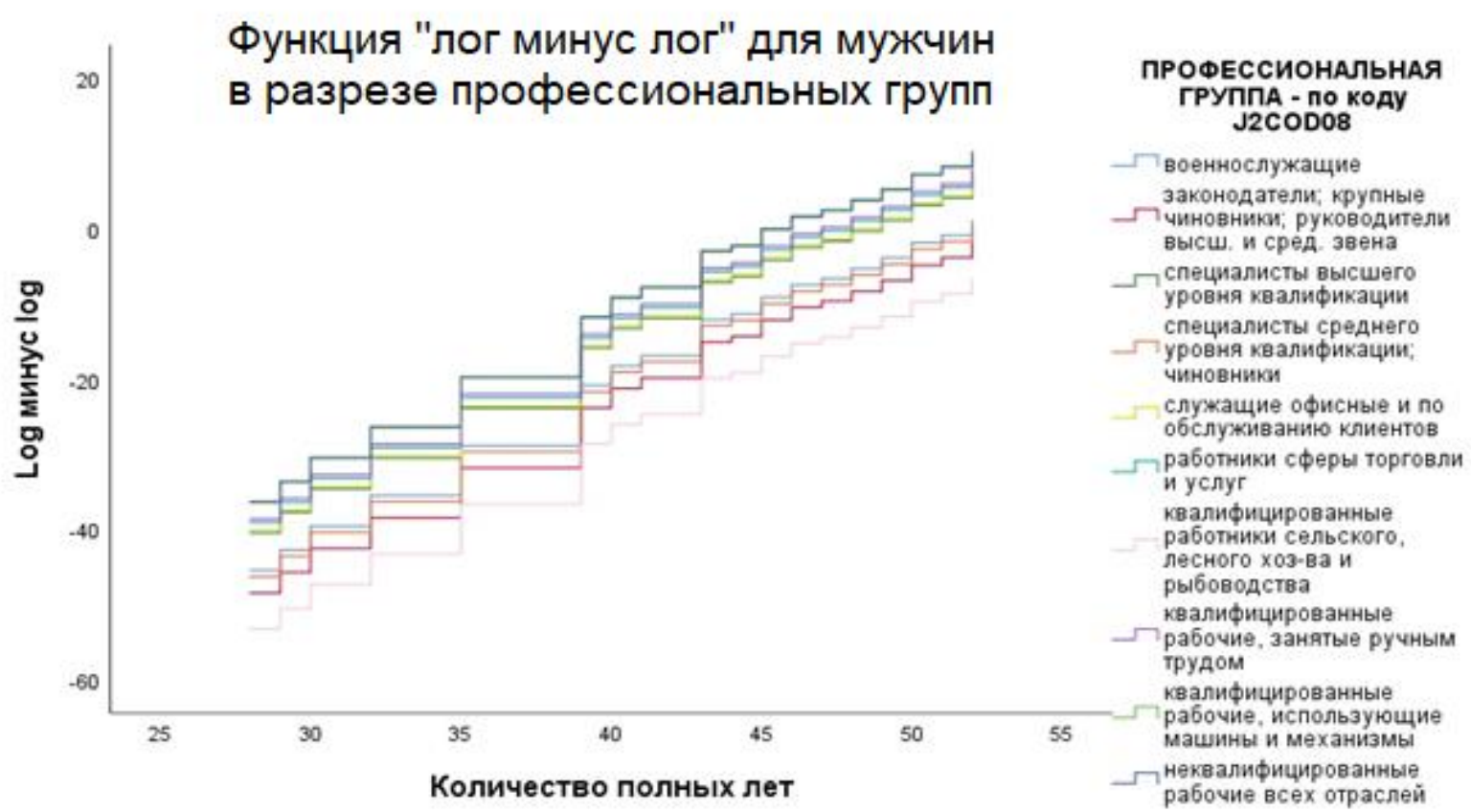

Рисунок П1.2. График «лог минус лог» в разрезе профессиональных групп, мужская подвыборка

Источник: Построено авторами в программном пакете IBM SPSS.

Примечание: Построено на укрупнённых группах наблюдений. 
Это говорит о том, что при проведении регрессионного анализа с построением регрессий Кокса достаточно использовать ковариаты, не зависящие от времени.

Также для проверки гипотезы пропорциональности традиционно применяется ещё один тест - на основе остатков Шонфельда (Schoenfeld residuals) (Cortese, Scheike, Martinussen 2010). В SPSS такая возможность отсутствует, однако реализация теста доступна, в частности, в программном пакете Stata. Тест устроен следующим образом: к каждой переменной добавляется временной эффект, выраженный переменной продолжительности или её логарифмом, и для каждой переменной тестируется гипотеза о равенстве этого временного эффекта нулю (этот эффект и именуется остатком Шонфельда). Если временной эффект для переменной статистически незначим, это говорит в пользу подтверждения гипотезы пропорциональности рисков. Однако в случае, если внутри одной категориальной переменной представлено слишком много категорий, проведение этого теста также становится затруднительным (допустим, у нас получилось, что для проживания в городе и на селе остатки Шонфельда значимо отличны от нуля, но для проживания в посёлке городского типа или областном центре равны нулю, в таком случае результаты теста не дадут нам ответ на вопрос, что делать с категориальной переменной местности проживания - устанавливать или не устанавливать её зависимой от времени) + технически установить ковариату зависимой от времени в SPSS можно только одну, что особенно затруднительны для категориальных ковариат, тем более с большим количеством категорий.

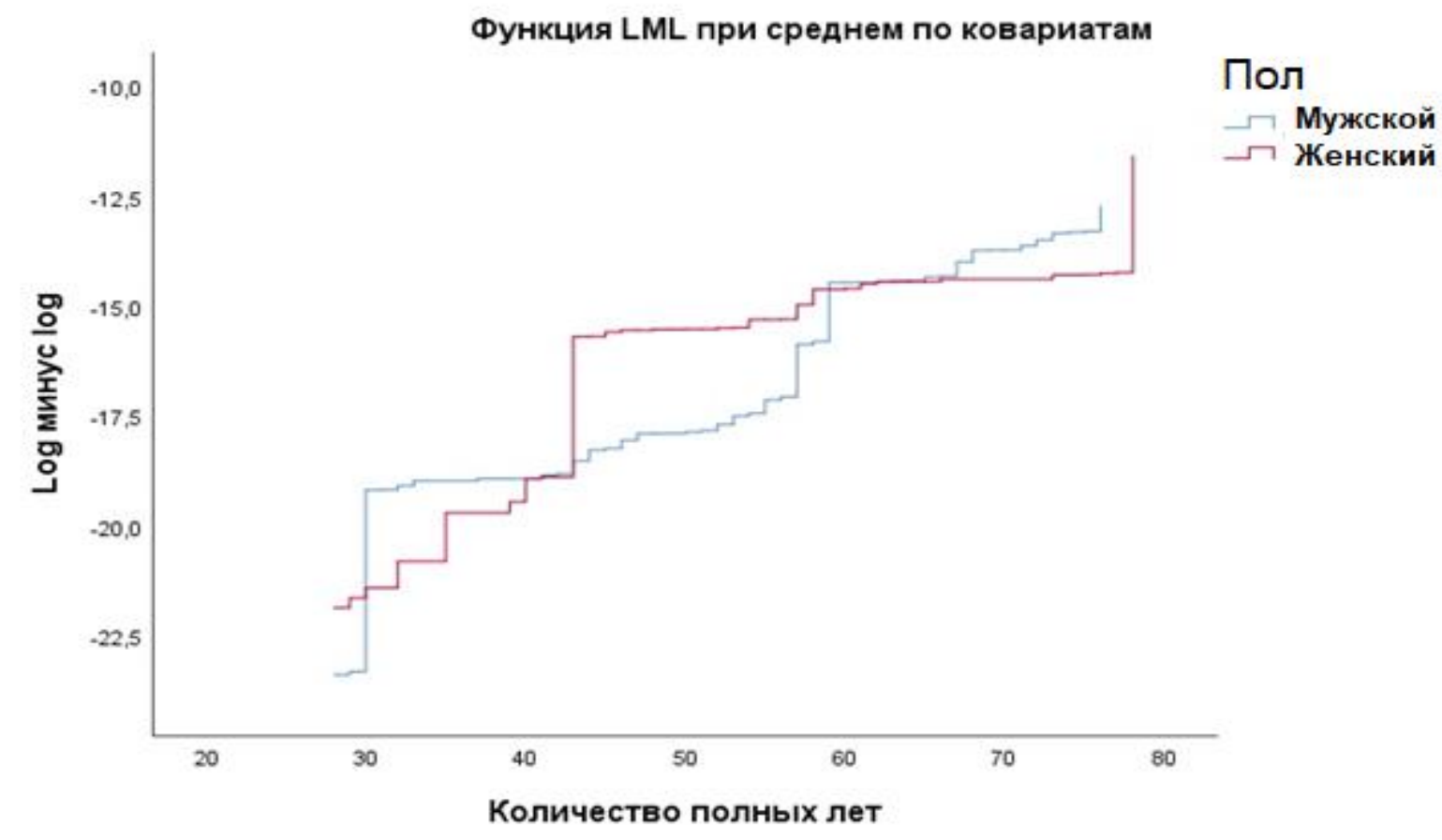

\section{Рисунок П1.3. Функция «лог минус лог» для мужчин и женщин на примере модели риска стать инвалидом II группы (с фактором самооценки здоровья)}

Источник: Построено авторами в программном пакете IBM SPSS. Примечание: Построено на укрупнённых группах наблюдений. 
Для разных полов действительно наблюдаются различия в рисках стать инвалидом (что мы наблюдаем через непараллельно идущие графики функций «лог минус лог» для мужчин и женщин на рисунке П1.3). Однако в силу того, что значения этого параметра очевидным образом фиксированы во времени ${ }^{3}$, наиболее подходящей для решения задачи исследования нам представляется стратифицированная модель пропорциональных рисков.

Техника построения этой модели состоит в том, что межгендерные различия в риске стать инвалидом находят отражение в различных величинах базового риска стать инвалидом для мужчин и женщин. Значения же коэффициентов модели полагаются одинаковыми для обоих полов (Cleves 2010).

\section{П1. Описательные статистики переменных}

Ниже представлены исходные данные по описательным статистикам переменных до укрупнения групп.

Таблица П2.1. Исходные данные по описательным статистикам переменных

\begin{tabular}{l|c|c|r|r|r}
\hline & $\begin{array}{c}\text { Количество } \\
\text { наблюдений }\end{array}$ & Минимум & Максимум & Среднее & $\begin{array}{c}\text { Стандартное } \\
\text { отклонение }\end{array}$ \\
\hline Тип населённого пункта & 192657 & 1 & 4 & 2,19 & 1,218 \\
Семейное положение & 192657 & 1 & 6 & 2,71 & 1,214 \\
Профессиональная группа & 116614 & 0 & 9 & 4,75 & 2,581 \\
Наличие инвалидности & 159064 & 1 & 7 & 1,69 & 0,598 \\
Первая группа инвалидности & 192657 & 0 & 1 & 0,0028 & 0,05267 \\
Вторая группа инвалидности & 192657 & 0 & 1 & 0,0109 & 0,10398 \\
Третья группа инвалидности & 192657 & 0 & 1 & 0,0063 & 0,07939 \\
Количество полных лет & 192657 & 28 & 104 & 49,79 & 14,977 \\
Пол респондента & 192657 & 1 & 2 & 1,59 & 0,491 \\
Самооценка здоровья & 191568 & 1 & 5 & 3,1281 & 0,70420 \\
Уровень образования & 192286 & 1 & 6 & 4,37 & 1,383 \\
\hline
\end{tabular}

Источник: Построено авторами в программном пакете IBM SPSS.

\section{Таблица П2.2. Описательные статистики переменной «Образование»}

\begin{tabular}{|c|c|c|c|c|c|}
\hline \multicolumn{2}{|c|}{ Законченное образование (группа) } & Частота & $\%$ & Валидный \% & Накопленный \% \\
\hline \multirow[t]{7}{*}{ Валидные } & окончил 0 - 6 классов & 10065 & 5,2 & 5,2 & 5,2 \\
\hline & $\begin{array}{l}\text { незаконченное среднее } \\
\text { образование (7 - } 8 \text { классов) }\end{array}$ & 13836 & 7,2 & 7,2 & 12,4 \\
\hline & $\begin{array}{l}\text { незаконченное среднее } \\
\text { образование ( } 7 \text { - } 8 \text { классов) } \\
\text { + что-то еще }\end{array}$ & 12704 & 6,6 & 6,6 & 19,0 \\
\hline & $\begin{array}{l}\text { законченное среднее } \\
\text { образование }\end{array}$ & 61364 & 31,9 & 31,9 & 50,9 \\
\hline & $\begin{array}{l}\text { законченное среднее } \\
\text { специальное образование }\end{array}$ & 47386 & 24,6 & 24,6 & 75,6 \\
\hline & $\begin{array}{l}\text { законченное высшее } \\
\text { образование и выше }\end{array}$ & 46931 & 24,4 & 24,4 & 100,0 \\
\hline & Всего & 192286 & 99,8 & 100,0 & \\
\hline Пропущенные & Системные & 371 & 0,2 & & \\
\hline
\end{tabular}

Источник: Построено авторами в программном пакете IBM SPSS.

\footnotetext{
${ }^{3}$ Данные о принадлежности респондентов к трансгендерам в обследовании не представлены
} 
Таблица П2.3. Описательные статистики переменной «Тип населенного пункта»

\begin{tabular}{|c|c|c|c|c|c|}
\hline \multicolumn{2}{|c|}{ Тип населенного пункта } & Частота & $\%$ & Валидный \% & Накопленный \% \\
\hline \multirow[t]{5}{*}{ Валидные } & Областной центр & 83325 & 40,3 & 40,3 & 40,3 \\
\hline & Город & 55826 & 27,0 & 27,0 & 67,3 \\
\hline & ПГТ & 13578 & 6,6 & 6,6 & 73,8 \\
\hline & Село & 54173 & 26,2 & 26,2 & 100,0 \\
\hline & Всего & 206902 & 100,0 & 100,0 & \\
\hline
\end{tabular}

Источник: Построено авторами в программном пакете IBM SPSS.

Таблица П2.4. Описательные статистики переменной «Семейное положение»

\begin{tabular}{|c|c|c|c|c|c|}
\hline \multicolumn{2}{|c|}{ Семейное положение в текущей волне } & Частота & $\%$ & Валидный \% & Накопленный \% \\
\hline \multirow[t]{8}{*}{ Валидные } & Никогда в браке не состояли & 11655 & 5,6 & 5,6 & 5,6 \\
\hline & $\begin{array}{l}\text { Состоите в } \\
\text { зарегистрированном браке }\end{array}$ & 111435 & 53,9 & 53,9 & 59,6 \\
\hline & $\begin{array}{l}\text { Живете вместе, но не } \\
\text { зарегистрированы }\end{array}$ & 20493 & 9,9 & 9,9 & 69,5 \\
\hline & $\begin{array}{l}\text { Разведены и в браке не } \\
\text { состоите }\end{array}$ & 19676 & 9,5 & 9,5 & 79,0 \\
\hline & Вдовец (вдова) & 28511 & 13,8 & 13,8 & 92,8 \\
\hline & $\begin{array}{l}\text { Официально } \\
\text { зарегистрированы, но вместе } \\
\text { не живут }\end{array}$ & 887 & 0,4 & 0,4 & 93,3 \\
\hline & Состоите в браке & 13921 & 6,7 & 6,7 & 100,0 \\
\hline & Всего & 206578 & 99,8 & 100,0 & \\
\hline Пропущенные & Системные & 324 & 0,2 & & \\
\hline Всего & & 206902 & 100,0 & & \\
\hline
\end{tabular}

Источник: Построено авторами в программном пакете IBM SPSS.

Таблица П2.5. Описательные статистики переменной «Профессиональная группа»

\begin{tabular}{|c|c|c|c|c|c|}
\hline \multicolumn{2}{|c|}{ Профессиональная группа - по коду J2COD08 } & Частота & $\%$ & Валидный \% & Накопленный \% \\
\hline \multirow[t]{11}{*}{ Валидные } & военнослужащие & 776 & 0,4 & 0,6 & 0,6 \\
\hline & $\begin{array}{l}\text { законодатели; крупные } \\
\text { чиновники; руководители } \\
\text { высшего и среднего звена }\end{array}$ & 9264 & 4,5 & 7,4 & 8,0 \\
\hline & $\begin{array}{l}\text { специалисты высшего уровня } \\
\text { квалификации }\end{array}$ & 22718 & 11,0 & 18,1 & 26,1 \\
\hline & $\begin{array}{l}\text { специалисты среднего уровня } \\
\text { квалификации; чиновники }\end{array}$ & 21039 & 10,2 & 16,7 & 42,8 \\
\hline & $\begin{array}{l}\text { служащие офисные и по } \\
\text { обслуживанию клиентов }\end{array}$ & 6335 & 3,1 & 5,0 & 47,8 \\
\hline & $\begin{array}{l}\text { работники сферы торговли и } \\
\text { услуг }\end{array}$ & 19634 & 9,5 & 15,6 & 63,5 \\
\hline & $\begin{array}{l}\text { квалифицированные работники } \\
\text { сельского, лесного хозяйства и } \\
\text { рыбоводства }\end{array}$ & 556 & 0,3 & 0,4 & 63,9 \\
\hline & квалифицированные рабочие, & 17235 & 8,3 & 13,7 & 77,6 \\
\hline & $\begin{array}{l}\text { квалифицированные рабочие, } \\
\text { использующие машины и } \\
\text { механизмы }\end{array}$ & 18903 & 9,1 & 15,0 & 92,6 \\
\hline & $\begin{array}{l}\text { неквалифицированные рабочие } \\
\text { всех отраслей }\end{array}$ & 9248 & 4,5 & 7,4 & 100,0 \\
\hline & Всего & 125708 & 60,8 & 100,0 & \\
\hline Пропущенные & Системные & 81194 & 39,2 & & \\
\hline Всего & & 206902 & 00,0 & & \\
\hline
\end{tabular}

Источник: Построено авторами в программном пакете IBM SPSS. 


\section{Таблица П2.6. Описательные статистики переменной «Назначена ли Вам группа} инвалидности?»

\begin{tabular}{|c|c|c|c|c|c|}
\hline \multicolumn{2}{|c|}{$\begin{array}{l}\text { Скажите, пожалуйста, назначена ли Вам какая- } \\
\text { нибудь группа по инвалидности? }\end{array}$} & Частота & $\%$ & Валидный \% & Накопленный \% \\
\hline \multirow[t]{8}{*}{ Валидные } & Да & 3919 & 1,9 & 2,5 & 2,5 \\
\hline & Нет & 154986 & 74,9 & 97,3 & 99,8 \\
\hline & $\begin{array}{l}\text { Ребенок-инвалид (для } \\
\text { респондентов младше 18-ти } \\
\text { лет) }\end{array}$ & 1 & 0,0 & 0,0 & 99,8 \\
\hline & Оформляет документы & 283 & 0,1 & 0,2 & 100,0 \\
\hline & Затрудняюсь ответить & 19 & 0,0 & 0,0 & 100,0 \\
\hline & Отказ от ответа & 21 & 0,0 & 0,0 & 100,0 \\
\hline & Нет ответа & 25 & 0,0 & 0,0 & 100,0 \\
\hline & Всего & 159254 & 77,0 & 100,0 & \\
\hline Пропущенные & Системные & 47648 & 23,0 & & \\
\hline Всего & & 206902 & 100,0 & & \\
\hline
\end{tabular}

Источник: Построено авторами в программном пакете IBM SPSS.

Таблица П2.7. Описательные статистики переменной «Какая группа инвалидности Вам назначена?»

\begin{tabular}{llr|r|r|r}
\hline Какая группа инвалидности Вам назначена? & Частота & \multicolumn{1}{c}{$\%$} & Валидный \% & Накопленный \% \\
\hline Валидные & О & 154986 & 74,9 & 97,5 & 97.5 \\
& Первая & 537 & 0,3 & 0,3 & 97.9 \\
Вторая & 2108 & 1,0 & 1,3 & 99.2 \\
Третья & 1223 & 0,6 & 0,8 & 100.0 \\
Затрудняюсь ответить & 19 & 0,0 & 0,0 & 100.0 \\
& Отказ от ответа & 6 & 0,0 & 0,0 & 100.0 \\
& Нет ответа & 26 & 0,0 & 0,0 & 100.0 \\
Пропущенные & 158905 & 76,8 & 100,0 & \\
Всего & Всего & 47997 & 23,2 & & \\
\hline
\end{tabular}

Источник: Построено авторами в программном пакете IBM SPSS.

Таблица П2.8. Описательные статистики переменной «Пол респондента»

\begin{tabular}{|c|c|c|c|c|c|}
\hline \multicolumn{2}{|c|}{ Пол респондента } & Частота & $\%$ & Валидный \% & Накопленный \% \\
\hline \multirow[t]{3}{*}{ Валидные } & Мужской & 85603 & 41,4 & 41,4 & 41,4 \\
\hline & Женский & 121299 & 58,6 & 58,6 & 100,0 \\
\hline & Всего & 206902 & 100,0 & 100,0 & \\
\hline
\end{tabular}

Источник: Построено авторами в программном пакете IBM SPSS.

Таблица П2.9. Описательные статистики переменной «Самооценка здоровья»

\begin{tabular}{lcr|r|r|r}
\hline Самооценка здоровья по 5-балльной шкале & Частота & $\%$ & Валидный \% & Накопленный \% \\
\hline Валидные & 1,00 & 3981 & 1,9 & 1,9 & 1,9 \\
& 25851 & 12,5 & 12,6 & 14,5 \\
& 3,00 & 119457 & 57,7 & 58,1 & 72,6 \\
& 4,00 & 54086 & 26,1 & 26,3 & 100,0 \\
Пропущенные & 5,00 & 2374 & 1,1 & 1,2 & 100,0 \\
Всего & Всего & 205749 & 99,4 & & \\
\hline
\end{tabular}

Источник: Построено авторами в программном пакете IBM SPSS. 
Таблица П2.10. Описательные статистики переменной «Возраст»

\begin{tabular}{|c|c|c|c|c|}
\hline Количество полных лет & Частота & $\%$ & Валидный \% & Накопленный \% \\
\hline Валидные 28 & 5592 & 2,7 & 2,7 & 2.7 \\
\hline 29 & 5503 & 2,7 & 2,7 & 5.4 \\
\hline 30 & 5552 & 2,7 & 2,7 & 8.0 \\
\hline 31 & 5461 & 2,6 & 2,6 & 10.7 \\
\hline 32 & 5495 & 2,7 & 2,7 & 13.3 \\
\hline 33 & 5423 & 2,6 & 2,6 & 16.0 \\
\hline 34 & 5397 & 2,6 & 2,6 & 18.6 \\
\hline 35 & 5275 & 2,5 & 2,5 & 21.1 \\
\hline 36 & 5262 & 2,5 & 2,5 & 23.7 \\
\hline 37 & 5121 & 2,5 & 2,5 & 26.1 \\
\hline 38 & 5139 & 2,5 & 2,5 & 28.6 \\
\hline 39 & 5045 & 2,4 & 2,4 & 31.1 \\
\hline 40 & 5096 & 2,5 & 2,5 & 33.5 \\
\hline 41 & 4955 & 2,4 & 2,4 & 35.9 \\
\hline 42 & 4899 & 2,4 & 2,4 & 38.3 \\
\hline 43 & 4789 & 2,3 & 2,3 & 40.6 \\
\hline 44 & 4690 & 2,3 & 2,3 & 42.9 \\
\hline 45 & 4745 & 2,3 & 2,3 & 45.2 \\
\hline 46 & 4660 & 2,3 & 2,3 & 47.4 \\
\hline 47 & 4567 & 2,2 & 2,2 & 49.6 \\
\hline 48 & 4453 & 2,2 & 2,2 & 51.8 \\
\hline 49 & 4353 & 2,1 & 2,1 & 53.9 \\
\hline 50 & 4310 & 2,1 & 2,1 & 56.0 \\
\hline 51 & 4248 & 2,1 & 2,1 & 58.0 \\
\hline 52 & 4145 & 2,0 & 2,0 & 60.0 \\
\hline 53 & 4201 & 2,0 & 2,0 & 62.0 \\
\hline 54 & 4162 & 2,0 & 2,0 & 64.1 \\
\hline 55 & 4124 & 2,0 & 2,0 & 66.1 \\
\hline 56 & 4043 & 2,0 & 2,0 & 68.0 \\
\hline 57 & 3981 & 1,9 & 1,9 & 69.9 \\
\hline 58 & 3807 & 1,8 & 1,8 & 71.8 \\
\hline 59 & 3728 & 1,8 & 1,8 & 73.6 \\
\hline 60 & 3539 & 1,7 & 1,7 & 75.3 \\
\hline 61 & 3384 & 1,6 & 1,6 & 76.9 \\
\hline 62 & 3263 & 1,6 & 1,6 & 78.5 \\
\hline 63 & 3245 & 1,6 & 1,6 & 80.1 \\
\hline 64 & 3125 & 1,5 & 1,5 & 81.6 \\
\hline 65 & 2995 & 1,4 & 1,4 & 83.0 \\
\hline 66 & 2847 & 1,4 & 1,4 & 84.4 \\
\hline 67 & 2679 & 1,3 & 1,3 & 85.7 \\
\hline 68 & 2563 & 1,2 & 1,2 & 86.9 \\
\hline 69 & 2411 & 1,2 & 1,2 & 88.1 \\
\hline 70 & 2349 & 1,1 & 1,1 & 89.2 \\
\hline 71 & 2280 & 1,1 & 1,1 & 90.3 \\
\hline 72 & 2153 & 1,0 & 1,0 & 91.4 \\
\hline 73 & 1993 & 1,0 & 1,0 & 92.3 \\
\hline 74 & 1907 & 0,9 & 0,9 & 93.3 \\
\hline 75 & 1806 & 0,9 & 0,9 & 94.1 \\
\hline 76 & 1740 & 0,8 & 0,8 & 95.0 \\
\hline 77 & 1528 & 0,7 & 0,7 & 95.7 \\
\hline 78 & 1370 & 0,7 & 0,7 & 96.4 \\
\hline 79 & 1215 & 0,6 & 0,6 & 97.0 \\
\hline 80 & 1087 & 0,5 & 0,5 & 97.5 \\
\hline 81 & 903 & 0,4 & 0,4 & 97.9 \\
\hline 82 & 775 & 0,4 & 0,4 & 98.3 \\
\hline
\end{tabular}

WWW.DEMREVIEW.HSE.RU 
Кучмаева, Калмыкова, Колотуша. Моделирование риска стать инвалидом в россии: оценка по данным выборочного лонгитюдного исследования

\begin{tabular}{crrr|r}
\hline Количество полных лет & Частота & $\%$ & Валидный \% & Накопленный \% \\
\hline 83 & 650 & 0,3 & 0,3 & 98.6 \\
84 & 604 & 0,3 & 0,3 & 98.9 \\
85 & 476 & 0,2 & 0,2 & 99.1 \\
86 & 438 & 0,2 & 0,2 & 99.3 \\
87 & 330 & 0,2 & 0,2 & 99.5 \\
88 & 289 & 0,1 & 0,1 & 99.6 \\
89 & 205 & 0,1 & 0,1 & 99.7 \\
90 & 154 & 0,1 & 0,1 & 99.8 \\
91 & 124 & 0,1 & 0,1 & 99.9 \\
92 & 74 & 0,0 & 0,0 & 99.9 \\
93 & 52 & 0,0 & 0,0 & 99.9 \\
94 & 38 & 0,0 & 0,0 & 100.0 \\
95 & 23 & 0,0 & 0,0 & 100.0 \\
96 & 18 & 0,0 & 0,0 & 100.0 \\
97 & 13 & 0,0 & 0,0 & 100.0 \\
98 & 11 & 0,0 & 0,0 & 100.0 \\
99 & 8 & 0,0 & 0,0 & 100.0 \\
100 & 7 & 0,0 & 0,0 & 100.0 \\
101 & 4 & 0,0 & 0,0 & 100.0 \\
102 & 4 & 0,0 & 0,0 & 100.0 \\
103 & 1 & 0,0 & 0,0 & 100.0 \\
104 & 1 & 0,0 & 0,0 & 100.0 \\
Всег & & 100,0 &
\end{tabular}

Источник: Построено авторами в программном пакете IBM SPSS. 
П3. Матрица коэффициентов сопряэённости Пирсона

\begin{tabular}{|c|c|c|c|c|c|c|c|c|c|c|c|c|c|c|c|c|c|}
\hline & MARST1 & MARST2 & MARST3 & MARST4 & MARST5 & MARST6 & MARST7 & SETTLE1 & SETTLE2 & SETTLE3 & SETTLE4 & OCCUP1 & OCCUP2 & OCCUP3 & OCCUP4 & OCCUP5 & OCCUP6 \\
\hline MARST1 & 1 & 0,059 & \begin{tabular}{|l|}
0,045 \\
\end{tabular} & \begin{tabular}{|l|}
0,24 \\
\end{tabular} & \begin{tabular}{|l|}
0,454 \\
\end{tabular} & 0,042 & \begin{tabular}{|l|}
0,025 \\
\end{tabular} & \begin{tabular}{|l|}
0,154 \\
\end{tabular} & 0,086 & \begin{tabular}{|r|}
0,004 \\
\end{tabular} & 0,095 & 0,003 & \begin{tabular}{|l|l|} 
& 0,035 \\
\end{tabular} & $\begin{array}{r}0,094 \\
\end{array}$ & 0,056 & \begin{tabular}{|l|}
0,02 \\
\end{tabular} & $\begin{array}{r}0,04 \\
\end{array}$ \\
\hline MARST2 & 0,059 & 1 & 0,013 & 0,072 & 0,147 & 0,012 & 0,007 & 0,014 & 0,003 & 0,001 & 0,012 & 0,012 & 0,016 & 0,037 & 0,035 & 0,008 & 0,014 \\
\hline MARST3 & 0,045 & 0,013 & 1 & 0,055 & 0,114 & 0,009 & 0,006 & 0,022 & 0,022 & 0,006 & 0,006 & 0,006 & 0,006 & 0,021 & 0,009 & 0,001 & 0,009 \\
\hline MARST4 & 0,24 & 0,072 & 0,055 & 1 & 0,527 & 0,051 & 0,031 & 0,04 & 0,044 & 0,021 & 0,104 & 0,011 & 0,008 & 0,047 & 0,02 & 0,001 & 0,005 \\
\hline MARST5 & 0,454 & 0,147 & 0,114 & 0,527 & 1 & 0,105 & 0,063 & 0,159 & 0,035 & 0,023 & 0,162 & 0,009 & 0,014 & 0,026 & 0,041 & 0,014 & 0,042 \\
\hline MARST 6 & 0,042 & 0,012 & 0,009 & 0,051 & 0,105 & 1 & 0,005 & 0,009 & 0 & 0,004 & 0,014 & 0,005 & 0,019 & 0,045 & 0,032 & 0,016 & 0,017 \\
\hline MARST7 & 0,025 & 0,007 & 0,006 & 0,031 & 0,063 & 0,005 & 1 & 0,008 & 0,014 & 0,002 & 0,023 & 0,002 & 0,02 & 0,001 & 0,016 & 0,005 & 0,022 \\
\hline SETTLE1 & 0,154 & 0,014 & 0,022 & 0,04 & 0,159 & 0,009 & 0,008 & 1 & 0,474 & 0,211 & 0,445 & 0,014 & 0,027 & 0,073 & 0,02 & 0,022 & 0,021 \\
\hline SETTLE2 & 0,086 & 0,003 & 0,022 & 0,044 & 0,035 & 0 & 0,014 & 0,474 & 1 & 0,143 & 0,316 & 0,01 & 0,035 & 0,022 & 0,041 & 0,024 & 0,023 \\
\hline SETTLE3 & 0,004 & 0,001 & 0,006 & 0,021 & 0,023 & 0,004 & 0,002 & 0,211 & 0,143 & 1 & 0,132 & 0,016 & 0,002 & 0,022 & 0,031 & 0,065 & 0,026 \\
\hline SETTL4 & 0,095 & 0,012 & 0,006 & 0,104 & 0,162 & 0,014 & 0,023 & 0,445 & 0,316 & 0,132 & 1 & 0,018 & 0,005 & 0,057 & 0,044 & 0,043 & 0,04 \\
\hline OCCUP1 & 0,003 & 0,012 & 0,006 & 0,011 & 0,009 & 0,005 & 0,002 & 0,014 & 0,01 & 0,016 & 0,018 & 1 & 0,011 & 0,022 & 0,018 & 0,01 & 0,019 \\
\hline OCCUP2 & 0,035 & 0,016 & 0,006 & 0,008 & 0,014 & 0,019 & 0,02 & 0,027 & 0,035 & 0,002 & 0,005 & 0,011 & 1 & 0,142 & 0,12 & 0,063 & 0,122 \\
\hline OCCUP3 & 0,094 & 0,037 & 0,021 & 0,047 & 0,026 & 0,045 & 0,001 & 0,073 & 0,022 & 0,022 & 0,057 & 0,022 & 0,142 & 1 & 0,24 & 0,129 & 0,245 \\
\hline OCCUP4 & 0,056 & 0,035 & 0,009 & 0,02 & 0,041 & 0,032 & 0,016 & 0,02 & 0,041 & 0,031 & 0,044 & 0,018 & 0,12 & 0,24 & 1 & 0,108 & 0,208 \\
\hline OCCUP5 & 0,02 & 0,008 & 0,001 & 0,001 & 0,014 & 0,016 & 0,005 & 0,022 & 0,024 & 0,065 & 0,043 & 0,01 & 0,063 & 0,129 & 0,108 & 1 & 0,111 \\
\hline OCCUP6 & 0,04 & 0,014 & 0,009 & 0,005 & 0,042 & 0,017 & 0,022 & 0,021 & 0,023 & 0,026 & 0,04 & 0,019 & 0,122 & 0,245 & 0,208 & 0,111 & 1 \\
\hline OCCUP7 & 0,034 & 0,002 & 0,013 & 0,016 & 0,022 & 0,009 & 0,027 & 0,067 & 0,045 & 0,048 & 0,112 & 0,003 & 0,019 & 0,039 & 0,033 & 0,017 & 0,034 \\
\hline OCCUP8 & 0,027 & 0,053 & 0,009 & 0,067 & 0,087 & 0,059 & 0,017 & 0,007 & 0,035 & 0,028 & 0,032 & 0,013 & 0,087 & 0,177 & 0,149 & 0,079 & 0,153 \\
\hline OCCUP9 & 0,033 & 0,008 & 0,005 & 0,038 & 0,021 & 0,033 & 0,017 & 0,041 & 0,007 & 0,041 & 0,073 & 0,011 & 0,075 & 0,153 & 0,129 & 0,068 & 0,132 \\
\hline OCCUP10 & 0,082 & 0,039 & 0,029 & 0,02 & 0,131 & 0,007 & 0,002 & 0 & 0,029 & 0,035 & 0,059 & 0,015 & 0,098 & 0,197 & 0,167 & 0,089 & 0,171 \\
\hline GENDER & 0,15 & 0,099 & 0,034 & 0,139 & 0,273 & 0,064 & 0,049 & 0,058 & 0,031 & 0,002 & 0,037 & 0,046 & 0,014 & 0,12 & 0,094 & 0,091 & 0,098 \\
\hline
\end{tabular}




\begin{tabular}{|c|c|c|c|c|c|}
\hline & OCCUP7 & OCCUP8 & OCCUP9 & OCCUP10 & GENDER \\
\hline MARST1 & 0,034 & \begin{tabular}{|l|}
0,027 \\
\end{tabular} & 0,033 & 0,082 & 0,15 \\
\hline MARST2 & 0,002 & 0,053 & 0,008 & 0,039 & 0,099 \\
\hline MARST3 & 0,013 & 0,009 & 0,005 & 0,029 & 0,034 \\
\hline MARST4 & 0,016 & 0,067 & 0,038 & 0,02 & 0,139 \\
\hline MARST5 & 0,022 & 0,087 & 0,021 & 0,131 & 0,273 \\
\hline MARST6 & 0,009 & 0,059 & 0,033 & 0,007 & 0,064 \\
\hline MARST7 & 0,027 & 0,017 & 0,017 & 0,002 & 0,049 \\
\hline SEITLE1 & 0,067 & 0,007 & 0,041 & 0 & 0,058 \\
\hline SETTLE2 & 0,045 & 0,035 & 0,007 & 0,029 & 0,031 \\
\hline SEITLE3 & 0,048 & 0,028 & 0,041 & 0,035 & 0,002 \\
\hline SETTLE4 & 0,112 & 0,032 & 0,073 & 0,059 & 0,037 \\
\hline OCCUP1 & 0,003 & 0,013 & 0,011 & 0,015 & 0,046 \\
\hline OCCUP2 & 0,019 & 0,087 & 0,075 & 0,098 & 0,014 \\
\hline OCCUP3 & 0,039 & 0,177 & 0,153 & 0,197 & 0,12 \\
\hline OCCUP4 & 0,033 & 0,149 & 0,129 & 0,167 & 0,094 \\
\hline OCCUP5 & 0,017 & 0,079 & 0,068 & 0,089 & 0,091 \\
\hline OCCUP6 & 0,034 & 0,153 & 0,132 & 0,171 & 0,098 \\
\hline OCCUP7 & 1 & 0,024 & 0,021 & 0,027 & 0,088 \\
\hline OCCUP8 & 0,024 & 1 & 0,094 & 0,122 & 0,328 \\
\hline OCCUP9 & 0,021 & 0,094 & 1 & 0,106 & 0,175 \\
\hline OCCUP10 & 0,027 & 0,122 & 0,106 & 1 & 0,034 \\
\hline GENDER & 0,088 & 0,328 & 0,175 & 0,034 & \\
\hline
\end{tabular}

Примечание: Обычный шрифт - коэффициенты не значимы.

Курсив - коэффицичент значим на уровне 0,1 (двухсторонняя).

Полужирный шрифт - коэффициент значим на уровне 0,05 (двухсторонняя).

Полужирный курсив - коэффициент значим на уровне 0,01 (двухсторонняя).

Число наблюдений для разных переменных варьируется от 158 mыс. до 353 mыс. 


\title{
MODELING THE RISK OF BECOMING DISABLED IN RUSSIA: AN ASSESSMENT BASED ON THE RUSSIAN LONGITUDINAL MONITORING SURVEY
}

\section{OKSANA KuChMaEVa, NATALia KalmyKOVA, ANTON KolOTUSHA}

\begin{abstract}
The article is devoted to modeling disability risk in Russia based on microdata. The need to assess the risk of becoming disabled is due to the significant scale of disabilities in Russia and their differentiation for sociodemographic groups of the population. The aim of the study is to determine the factors influencing the risk of disability in Russia. The difficulty of assessing the risk of disability is associated with the lack of representative monitoring surveys of disability, as well as data on mortality of persons with disabilities, including by age groups and diseases. To model the risk of becoming disabled, data from the Russian Monitoring of Economy and Health (NRU HSE) were used for the period from 2003 to 2018. The sample size was more than 125 thousand respondents, of which 519 individuals received a disability. Based on Cox regressions, a series of survival models was built to assess the influence of socio-economic factors on the risk of a healthy person becoming disabled. The IBMSPSS 25.0 software package was used for the calculations. The most noticeable risk of disability increases for men and women after the age of 50 and reaches $3-4 \%$ by the age of 60 . There are differences in the risk of becoming disabled for men and women, as well as depending on the level of education, marital status and area of residence. The presence of a significant excess of the risk of becoming disabled among representatives of certain professional groups was revealed. The highest risk of becoming disabled in group 2 is observed among specialists of the highest and average qualifications, office workers and specialists in working with clients, workers in the trade and services sector, as well as among qualified workers in agriculture, forestry and fishing. Differentiation of the risk of becoming disabled in old age is due to accumulated health defects, in a significant part of cases those associated with professional activities, as well as to varying degrees of access to medical services and disability information.
\end{abstract}

Key words: disability in Russia, risk of becoming disabled, disability factors, Cox regression, probability of disability, disability factors, sources of data on disability.

OKSANA KuchmaEva (kuchmaeva@yandex.ru), Lomonosov Moscow State University, Russia.

NATAlia KalmyKova (natalia@econ.msu.ru), Lomonosov Moscow State University, Russia.

Anton Kolotusha (tony_kol@mail.ru), Lomonosov Moscow STATE University, Russia.

THE STUDY WAS SUPPORTED BY THE RFBR, PROJECT «INFLUENCE OF HUMAN CAPITAL ON PRESENT AND FUTURE ECONOMIC GROWTH IN RUSSIA» (GRANT №19-29-O7546).

DATE RECEIVED : OCTOBER 2020.

\section{REFERENCES}

Adler N.E., Snibbe A.C. (2003). The role of psychosocial processes in explaining the gradient between socioeconomic status and health. Current Directions in Psychological Science, 12(4), 119-123. DOI: 10.1111/1467-8721.01245

Andersen P.K., Borch-Johnsen K., Deckert T., Green A., Hougaard P., Keiding N., Kreiner S. (1985). A Cox Regression Model for the Relative Mortality and Its Application to Diabetes Mellitus Survival Data. Biometrics, 41(4), 921. DOI: 10.2307/2530964 
Bellera C.A., MacGrogan G., Debled M., de Lara C.T., Brouste V., Mathoulin-Pélissier S. (2010). Variables with time-varying effects and the Cox model: some statistical concepts illustrated with a prognostic factor study in breast cancer. BMC Med Res Methodol. Mar 16, 10:20. DOI: 10.1186/1471-2288-10-20. PMID: 20233435; PMCID: PMC2846954

Brandström A., Broström G., Persson L.-A. (1984). The impact of feeding patterns on infant mortality in a nineteenth-century Swedish parish. J. Trop. Pediat, 40, 154-159. DOI: 10.1093/tropej/30.3.154

Broström G. (1987). The influence of mother's mortality on infant mortality: A case study in matched data survival analysis, Scandinavian Journal of Statistics, 14, 113-123. URL: https://www.jstor.org/stable/4616055

Brunello G., Fort M., Schneeweis N., Winter -Ebmer R. (2016). The causal effect of education on health: what is the role of health behaviors? Health Economics, 25(3), 314-336.

DOI: $10.1002 /$ hec. 3141

Burdyak A.Ya., Tyndik A.O. (2016). Measurement of disability and socio-economic status of disabled: the russian and international approaches. Vestnik NSUEM, 1, 22-43. (In Russ.) Retrieved from https://nsuem.elpub.ru/jour/article/view/610

Cleves M.A., Gould W.W., Gutierrez R.G. Marchenko Y.V. (2010). An Introduction to Survival Analysis Using Stata. 3rd ed. College Station, TX: Stata Press.

Cortese G., Scheike T.H, Martinussen T. (2010) Flexible survival regression modelling. Stat Methods Med Res. Feb; 19(1), 5-28. DOI: 10.1177/0962280209105022. Epub 2009 Jul 16. PMID: 19608605.

Cox D.R. (1972). Regression models and life tables (with discussion). Journal of the Royal StatisticalSociety, Series B (Methodological), 34, 187-220. URL: http://links.jstor.org/sici?sici=00359246\%281972\%2934\%3A2\%3C187\%3ARMAL\%3E2.0.CO\%3B2-6

Cutler D.M., Lleras-Muney A. (2010). The Education Gradient in Old Age Disability. In Wise D.A. (Ed.), Research Findings in the Economics of Aging (pp. 101-120). The University of Chicago Press. URL: http://www.nber.org/chapters/c8194

Demianova A., Lukiyanova A. (2017). How Substantial Is Employment Discrimination Against the Disabled in Russia? HSE Economic Journal, 21 (3), 385-411. (In Russ.). Retrieved from https://ej.hse.ru/2017-21-3/211112324.html

Demianova A., Lukiyanova A. L. (2016). The impact of disability status on the labor supply in Russia. Applied econometrics, (44), 50-74. (In Russ.).

Heiland E.G., Welmer A., Wang R., Santoni G., Fratiglioni L. (2019). Cardiovascular Risk Factors and the Risk of Disability in Older Adults: Variation by Age and Functional Status. Journal of the American Medical Directors Association, 20(2), 208-212.

Helgadóttir B., Narusyte J., Ropponen A., Bergström G., Mather L., Blom V., Svedberg P. (2019). The role of occupational class on the association between sickness absence and disability pension: A Swedish register-based twin study. Scandinavian Journal of Work Environment and Health, 45(6), 622-630. DOI: 10.5271/sjweh.3816

Högberg U., Wall S., Broström G. (1986). The impact of early medical technology on maternal mortality in late 19th century Sweden. International Journal of Gynecology \& Obstetrics, 24(4), 251-261. https://doi.org/10.1016/0020-7292(86)90081-0 22 
Ivanova A.E., Lopakov K.V., Zemlyanova E.V., Mihajlov A.YU. (2019). Social context of disability and disability in Russia. Social aspects of public health, 1(65). DOI: https://dx.doi.org/10.21045/2071-5021-2019-65-1-1 (In Russ.).

Invalidy v Rossii: prichiny i dinamika invalidnosti, protivorechiya i perspektivy social'noj politiki (1999) / [T. M. Maleva, S. A. Vasin, O. YU. Golodec, S. V. Besfamil'naya]; Byuro ekon. analiza. Moskva: ROSSPEN

Kalabihina I.E., Shajkenova ZH.K. (2019). Time spent on homework: determinants of gender inequality. Public opinion monitoring: economic and social changes, 3, 261-285. (In Russ.).

Kulagina E.V. (2016). Demograficheskie faktory invalidnosti: orientiry dlya gosudarstvennogo regulirovaniya i statistiki [Demographic factors of disability: guidelines for state regulation and statistics]. In V.I. Gerasimov, D.V. Efremenko (Ed.), Rossiya: tendencii i perspektivy razvitiya. Ezhegodnik [Russia: trends and prospects of development. Yearbook] (p 502-506). Moscow: RAN. INION. (In Russ.).

Kuchmaeva O.V. (2020). Employment of disabled people in Russian regions: state, differentiation, factors. Statistics and Economics, 17(5), 27-37. https://doi.org/10.21686/2500-3925-2020-5-27-37 (In Russ.).

Leineweber C., Marklund S., Aronsson G., Gustavsson K. (2019). Work-related psychosocial risk factors and risk of disability pension among employees in health and personal care: A prospective cohort study. International Journal of Nursing Studies, 93, 12-20. https://doi.org/10.1016/j.ijnurstu.2018.10.009

Lynch J.W., Smith G.D., Kaplan G.A., House J.S. (2000). Income inequality and mortality: importance to health of individual income, psychosocial environment, or material conditions. British Medical Journal, 320(7243), 1200-1204. DOI: 10.1136/bmj.320.7243.1200

Mackenbach J., de Jong J.P. (2018). Health Inequalities: an Interdisciplinary Exploration of Socioeconomic Position, Health and Causality. Amsterdam: FEAM/ALLEA Committee on Health Inequalities. Symposium Report. URL: https://www.allea.org/wpcontent/uploads/2018/11/Health_Inequalities_Symposium_Report.pdf

Makarenceva A.O., Vasin S.A., Hasanova R.R. (2016) Kak ocenit' chislo invalidov v Rossii // Demoskop Weekly. 695-696. URL: http://demoscope.ru/weekly/2016/0695/tema01.php

Maleva T.M. (Ed.) (2017). Invalidnost' i social'noe polozhenie invalidov v Rossii [Disability and social status of disabled people in Russia]. Moscow: Izdatel'skij dom «Delo» RANHiGS. (In Russ.).

Marmot M.G. (2004). The status syndrome. How social standing affects our health and longevity. New York: Henry Holt \& Company

McGregor D., Palarea-Albaladejo J., Dall P., Hron K., Chastin S. (2019). Cox regression survival analysis with compositional covariates: Application to modelling mortality risk from 24-h physical activity patterns. Statistical Methods in Medical Research, 29(5), 1447-1465. https://doi.org/10.1177/0962280219864125

Meshkov N.A., Buhtiyarov I.V., Val'ceva E.A. (2020). Assessment of professional activity risk factors and health status of fire service employees. Occupational medicine and industrial ecology. 60(10), 658-673. https://doi.org/10.31089/1026-9428-2020-60-10-658-673 (In Russ.).

National research University "Higher school of Economics" (2020). Russian monitoring of economic situation and population health (RLMS-HSE). Combined database 1994-2018. 
Households; Individuals. Waves 12-27. URL: http://www.cpc.unc.edu/projects/rlms; URL: http://www.hse.ru/rlms (data downloaded on 01.02.2020). (In Russ.).

Natsun L.N., Shabunova A.A. (2018). On the issue of economic cost of disability. Economic and Social Changes: Facts, Trends, Forecast, 11(2), 160-174. (In Russ.)

DOI: $10.15838 /$ esc.2018.2.56.11

Ramonov A. (2015). Integral indicators of demographic losses from deaths and injuries due to road accidents in Russia. Demographic Review, 2(4), 136-149. (In Russ.) https://doi.org/10.17323/demreview.v2i4.1771

Ramonov A., Pyankova A. (2014). Evaluating public health on the basis of census information. Demographic Review, 1(2), 140-155. (In Russ.) https://doi.org/10.17323/demreview.v1i2.1820

Ropponen A, Svedberg P. (2019). Risk factors of disability pensions - what will twin studies from Finland and Sweden add? European Journal of Public Health, V.29, Iss. Supplement 4, https://doi.org/10.1093/eurpub/ckz185.697

Rosstat (2018). Data from a Comprehensive survey of the population's living conditions. 2018. URL: https://rosstat.gov.ru/free_doc/new_site/KOUZ18/index.html

Rosstat (2016). Data from a Comprehensive survey of the population's living conditions. 2016. URL: https://rosstat.gov.ru/free_doc/new_site/KOUZ16/index.html

Rosstat (2020). The situation of disabled people. URL:https://rosstat.gov.ru/folder/13964

Rusinova N. (2019). Social inequalities in health: the mediating role of material deprivation and psychological resources. Demographic Review, 6(3), 6-30. (In Russ.) https://doi.org/10.17323/demreview.v6i3.9853

United Nations (2001). Guidelines and Principles for the Development of Disability Statistics. URL: https://unstats.un.org/unsd/publication/SeriesY/SeriesY_10r.pdf

Vasin S.A. (2017). Prospects of Changes in the Total Size and Age Composition of Adults with Disability in Russia // Studies on Russian Economic Development, 28(5), 558-567.

Vladimirova O.N., Bashkireva A.S., Korobov M.V., Lomonosova O.V., Khorkova O.V. (2017). Current trends of total disability on the background of the demographic development of Russia. Clinical gerontology, 5-6, 44-50. (In Russ.). Retrieved from https://kg.newdiamed.ru/issue/id38483/id38530

Vyal'shina A.A. (2020). Influence of the level of education on the health of the rural population. Social aspects of public health, 1(66). (In Russ.). DOI: 10.21045/2071-5021-2020-66-1-6

World Health Organisation (2011). World report on disability [Vsemirnyj doklad po invalidnosti]. Retrieved from http://www.who.int/disabilities/world_ report/2011/summary_ru.pdf

World Health Organization (2020). Ten facts on disability. URL: https://www.who.int/features/factfiles/disability/ru/ 